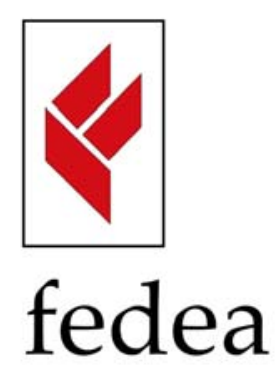

Fundación de

Estudios de

Economía Aplicada

The Determinants of Pricing in Pharmaceuticals:

Are U.S. prices really so high?

by

Antonio Cabrales*

Sergi Jiménez-Martín**

DOCUMENTO DE TRABAJO 2008-18

Serie Economía de la Salud y Hábitos de Vida

CÁTEDRA Fedea - la Caixa

May 2008

** Universidad Carlos III de Madrid and CEPR: antonio.cabrales@uc3m.es

*** Universitat Pompeu Fabra, FEDEA and CRES: sergi.jimenez@upf.edu

Los Documentos de Trabajo se distribuyen gratuitamente a las Universidades e Instituciones de Investigación que lo solicitan. No obstante están disponibles en texto completo a través de Internet: $h t t p: / / w w w . f e d e a . e s$.

These Working Paper are distributed free of charge to University Department and other Research Centres. They are also available through Internet: $h t t p: / / w w w . f e d e a . e s$.

ISSN:1696-750X 


\title{
The Determinants of Pricing in Pharmaceuticals: Are U.S. prices really so high?*
}

\author{
Antonio Cabrales ${ }^{\dagger} \quad$ Sergi Jiménez-Martín \\ version: April 2007 \\ printing date: May 21, 2008
}

\begin{abstract}
This paper studies price determination in pharmaceutical markets using data for 25 countries, six years and a comprehensive list of products from the MIDAS IMS database. A key finding is that the U.S. has prices that are not significantly higher than those of countries with similar income levels, specially those that are "lightly regulated". More importantly, price differences to the US levels increase for "branded" or innovative products, and decrease, regardless of the level of regulation for mature or widely diffused molecules. In addition, the nationality of the producer appears to have a small and often insignificant impact on prices. We have constructed a theoretical model that accounts for all these findings simultaneously. One interesting aspect of the model is that it shows that reference pricing confers a degree of protection against government intervention. Thus, there is a sense in which a reference price (or similar) policy in one country becomes a "commitment device" "to avoid lowering price in another one.
\end{abstract}

Keywords: Pharmaceutical prices. regulation.

JEL Classification: I10, I18, L18, L65

*This study was supported by an unrestricted educational grant from the Merck Company Foundation, the philanthropic arm of Merck \& Co. Inc., Whitehouse Station, NJ. Partial funding was also obtained from the Spanish Ministry of Science and Technology under grants SEC2003-03474 and SEJ2005-08783C04-01. We thank IMS for providing the data. The helpful suggestions of seminar audiences at CEMFI, Toulouse and IESE, and Félix Lobo, Gerard LLobet, Guillem López, Vicente Ortún, and Jaume Puig are gratefully acknowledged.

†Departamento de Economía, Universidad Carlos III de Madrid, FEDEA and CEPR, Madrid 126, 28903 Getafe, Spain. Email: antonio.cabrales@uc3m.es

‡Universitat Pompeu Fabra, FEDEA, and CRES. Address for correspondence: Departament d'Economia i Empresa, Ramon Trias Fargas 25-27, 08005 Barcelona, Spain. Email: sergi.jimenez@upf.edu 


\section{Introduction}

There are serious theoretical reasons for the existence of non-market interventions in the pharmaceutical industry. The presence of substantial R\&D and marketing (sunk) costs creates large barriers to entry, which limits the positive effects of competition. In addition, the consumer is typically insured, so she does not pay the full cost of the medicine. Furthermore, consumption often requires a prescription, and the prescribing physician is, in most cases, insulated from the economic aspects of the decision. This situation creates severe informational and incentive problems, which make some kind of government regulation (or insurance company control) potentially beneficial in theory. Indeed, Ballance et al. (1992) survey 56 nations and find that most countries impose some form of price controls. But the amount of regulation varies a great deal across countries, as they go from "substantial," to "limited," to "nonexistent." Even the form of regulation can be heterogeneous. As Scherer (2000) notes, the instruments can be: reference pricing, product per product negotiation, price caps, rate of return regulation and formula pricing.

The existence of theoretical reasons for price intervention does not imply that actual regulation is necessarily efficient. It may also exist to transfer rents from some groups of economic agents to others. A firm, which spends vast amounts of money to develop a new drug, necessarily has to expect large operating profits, after the discovery has been made. But at that time, it may be in the (short-term) interest of a government to impose low prices for the product in order to receive the goodwill of the consumers/voters. In addition, of course, the prices of pharmaceuticals depend on other economic factors, such as the usefulness of the products or the market power of the producers, in different degrees. Thus, the question of what determines actual regulation, rent-seeking or economic efficiency, deserves an empirical investigation.

In spite of this interest, there has been no systematic empirical study of the determinants of pricing in this industry for a large set of products and countries. ${ }^{1}$ In this paper we attempt to fill this vacuum. We study pricing in pharmaceuticals using a multicountry and multiproduct data set from the IMS MIDAS international dataset for the period 1998-2003. Our dataset encompasses a large number of countries including the top ten in terms of pharmaceutical expenditures, as well as other countries that are either smaller in size or with a lower income. The data comprises products from a large number of groups or anatomic classifications. The richness of the data allow us to study the determinant

\footnotetext{
${ }^{1}$ The existing studies mostly look at small groups of chemicals for a few countries (Lu and Comanor 1998, Danzon and Chao 2000a, 2000b Ekelund and Persson 2003).
} 
of price variation between countries, and we give special attention to both regulatory regimes and industrial structure.

Literature The work of Danzon and Chao (2000a, 2000b) is specially relevant for our purposes within the large literature on this topic. They study the effect of regulatory regimes on price setting. Their data includes seven big countries in terms of spending which are classified in terms of the severity of regulation. ${ }^{2}$ Danzon and Chao (2000a) estimate a reduced form equation where prices depend on quality attributes of the product and on the competition characteristics of the market. Their empirical results suggest that regulation limits the beneficial effect of competition. Using similar data, Danzon and Chao (2000b) demonstrate that the conventional view that drug prices are much higher in the US than in other countries is incorrect. The biased perception is due to the small, unrepresentative samples and to the inappropriate methods used in prior studies. In this paper we further confirm and amplify this view by showing, with a much larger database and a robust empirical strategy, that the U.S. prices are indeed in line with those of countries of similar income levels. In a similar vein, a study by the U.S. Department of Commerce (2004) has argued that the lower (income-adjusted) prices induced by regulation in the OECD countries, with respect to the U.S., hurts consumers in the long term through the lower incentive for $\mathrm{R} \& \mathrm{D}$ and thus through lower discovery of life-saving drugs. Domínguez, Ganuza and Llobet (2006) provide a theoretical counterargument. Price controls hurt small ("me-too") innovations more than the relatively price inelastic drastic innovations, and could even induce larger investment by focusing firms on the drastic innovations. We have a more fundamental challenge to the U.S. Department of Commerce (2004) results, since our more carefully income-adjusted prices do not show

\footnotetext{
${ }^{2}$ From more to less regulated, the first group includes Italy, France and Japan were launch prices are regulated and afterward are revised downwards over the drug's life cycle. The price of new varieties is related to the price of established varieties. In addition, consumer and physicians demand are expected to be inelastic due to insurance coverage, and generics substitution by pharmacists was not allowed in France and Italy at the time of the study. Moreover, pharmacies are paid a margin on the product price which may encourage the sale of more expensive products. The second group includes UK and Germany were corporations are free to set prices at launch but prices cannot increase (freely) later on. In addition, in both countries there is some type of upper bound to prices, implemented either through a reference price (Germany) or a maximum overall rate of return (UK). Generics substitution by pharmacists is the main source of price-demand elasticity, since they keep the margin between the reimbursement price and the manufacturers price. This is possible in UK, and to a lesser extent in Germany. The third group includes US and Canada where prices are free, consumers' and physicians' demands appear to be less inelastic and generic substitution on the side of the pharmacists is encouraged as a means to promote competition.
} 
that U.S. prices are indeed lower, in line with the results of Danzon and Chao for a smaller database.

Kyle (2007) examines the effect of price controls in the extent and timing of the launch of new drugs around the world and finds that regulation has a statistically and quantitatively important effect on pharmaceutical launches. The effect takes two forms. First, drugs invented by firms headquartered in countries that use price controls reach fewer markets and with longer delays than products that originate in countries without price controls. Second, companies delay launch into price-controlled markets, and are less likely to introduce their products in additional markets after entering a country with low prices. Launches into low price countries in Europe are further delayed after a regulatory change allowing parallel imports, which could potentially depress prices in high price markets. The findings of Kyle (2007) support our theoretical explanation for our own finding that the effect of the nationality of the producers on prices is negligible. We argue theoretically that the fear of reducing prices in markets with high prices leads producers to a strategically credible resistance to price reduction in more regulated countries.

In terms of empirical specification, previous evidence in this industry suggest that marginal costs are almost irrelevant in the industry and recommend the use of a hedonic price approach. For example, Berndt et al (1999) estimate a hedonic price equation that measures the price impact of drug attributes. Likewise, we do not attempt to estimate marginal cost effects on prices.

The effect of entry of generic products on price evolution has attracted recently a lot of attention. The empirical evidence on this issue is ambiguous. Some authors (Grabowski and Vernon 1992, and Caves, Whinston and Hurwitz 1991) report that brand-name prices increased after the entry of generic competition, while others (Wiggins and Maness, 1994) find a reduction in brand-name prices following entry. Finally, Frank and Salkever (1992 and 1997) report that brand name prices increased while generic products prices fell, producing a reduction in average prices. Our analysis shows that generics prices are indeed lower than those of brand name products, and we also show (see section 5.3), that the impact of the number of competitors depends on the therapeutical class analyzed (thus explaining the diverging results of earlier literature).

Empirical strategy and results Our empirical strategy introduces several innovations with respect to the previous empirical literature in the subject.

1. We estimate pricing equations separately for each country, and then we obtain estimates by pooling the countries. By pooling the sample we will be able to explore the interplay of cross-national variables and regulation in price setting. For example, 
by including as an explanatory variable the GDP per capita, or the ratio of public consumption to GDP, we can assess, in a very disaggregate context, whether higher prices are observed primarily in richer countries or in countries with larger public sectors. $^{3}$

2. We exploit the panel nature of the data and control for unobserved heterogeneity at the product level. By doing so, we control for time invariant factors that affect price setting. In particular we control for "unobserved" marginal effects. However, this comes at a cost, since this reduces notably the variation of the data. In this context, we identify the effect of time-invariant variables by following a two-stage procedure.

3. With the exception of products without consumption or information in a given period, we do not restrict the sample in any way. However, we do explore the sensitivity of our results to the restriction of the sample in several dimensions:

(a) The restriction to single molecule products, which has been explored in other studies. $^{4}$

(b) The variation of the sample to the number of countries where a corporation is present.

(c) The variation of the sample to the number of countries a molecule is present.

(d) The analysis by therapeutical category.

By exploring these dimensions we are able to assess the robustness of the results to the restriction of the sample, as well as the effects of increasing the "internationality" of the corporation or the "brandedness" of the products analyzed and the "diffusion" of molecules.

Our results show that variables related to the quality of the product are strongly significant in explaining the prices. For example, older products are less expensive, and recently approved ones command a price premium. There is also robust evidence in the data that market forces operate in the expected way. This can be seen in the fact in that larger firms (measured in different ways) tend to command higher prices, although

\footnotetext{
${ }^{3}$ Danzon and Furukawa (2003) suggest theoretically that fixed costs should be distributed across countries depending on demand elasticities, so that higher prices should be observed in richer countries. This suggests that in a multi-country study, like ours, variables with cross-country variation should be included in the regression.

${ }^{4}$ For example, Danzon and Chao (2000a).
} 
not strongly in quantitative terms. Also, generic products, which operate in off-patent markets (thus, probably more competitive ones) have lower prices.

Another interesting finding is that higher per-capita income produces higher prices in any given country, most likely derived from a lower price elasticity. ${ }^{5}$ There is also a positive effect on prices of a higher ratio of public consumption to GDP. The interpretation of this finding is less straightforward. Most likely, a higher public consumption to GDP also signals a low price elasticity, relative to countries with the same income, probably derived from higher insulation of consumers from prices through health insurance (as pointed out by Duggan and Scott-Morton 2006, in a very different context). The size of this effect depends on the level of regulation, and it is smaller for more regulated countries, where public sector exerts has significant barganing power, thus partly compensating the effect of insurance.

To understand the impact of regulation we classified the countries in our sample in three groups, from less to more regulated. ${ }^{6}$ We observe that the country fixed effect of more regulated countries tends, indeed, to be lower than that of the rest, although this is far from universal. For example, the fixed effect of the U.S.A. is significantly higher than that, of Canada (but not for all specifications), France or Italy. This means that if average prices in the U.S.A. are higher it is not because other countries engage in "free riding regulation," but because its per-capita income is higher.

Let us elaborate a bit more systematically on the price variation across countries, since this is one the main contributions of this paper. We can summarize our findings in this respect in four points.

1. Effect of regulation on price differences across countries:

(a) There are large and systematic differences in prices between the group of low regulated countries and a group of more highly regulated ones.

(b) There are not very large differences in prices within the group of low regulated countries (among which the U.S. is the largest market).

2. Effect of quality on price differences across countries:

\footnotetext{
${ }^{5}$ This supports empirically Danzon and Furukawa (2003, p. 534) observation that "the global joint costs should be recouped through price markups over marginal cost that differ based on income levels, assuming that income is a major determinant of "true" price elasticity. Thus, price differentials that are related to income would be consistent with both economic efficiency and equity."

${ }^{6}$ See section 4 for an explanation of the classification method.
} 
(a) The price differences increase when the product is distributed by truly global companies (present in all the countries of our sample), typically representing more innovative, or "branded" products.

(b) The price differences decrease when the molecule is present in all the countries of our sample, typically more mature, more widely diffused products.

3. Effect of corporation nationality on price differences:

(a) Foreign multinational companies do not experience noticeably different prices from local multinationals, even in relatively highly regulated countries.

(b) Products from exclusively local corporations have lower prices in practically all the countries.

Findings 1 and 2 can be interpreted as meaning that regulation is effective in bringing prices down, but specially so in the more innovative products, those that are produced and distributed by global companies around the world. On the other hand, for products that are common, in the sense of produced in all countries, but not by global companies (typically more advanced in their life cycles), the effect of regulation is vanishing. Thus, competition is at least as effective as regulation in bringing prices down, when applicable. Finding 3a suggests that even though one would expect governments to regulate more leniently their own firms, the multinationals are somehow protected. A reason for this may be that conceding a low price in one country would entail, through reference pricing, lower prices in many others. ${ }^{7}$ Finding $3 \mathrm{~b}$ may be due to the fact that products from purely local firms are perceived to have lower quality.

We present in section 2 a model which can account for all these findings. The model incorporates three types of countries: those that do not regulate prices at all, those which use an (external) reference price regulatory scheme, and those which regulate prices directly through price caps. As in our observations 1 and 2, the prices differences can be controlled (in different degrees) both through the regulatory schemes, or through the higher price elasticity that is associated with competition. Similarly, finding 3 can explain the small price "preferences" given to own country multinationals through the protection afforded to corporation via reference pricing.

The rest of the paper is structured as follows. We first present in section 2 a model which accounts for the empirical findings we discuss in later sections. Then, in section 3 , we present the empirical strategy. Section 4 explains the data and the construction of

\footnotetext{
${ }^{7}$ Reference pricing would act, thus, as the sort of best-price guarantee which has been criticized in the anti-trust literature (see Motta 2004).
} 
the variables employed. Section 5 presents the main results from the analysis. Finally, section 6 concludes.

\section{The model}

We now develop a model that is able to explain the positive relationship of prices with quality and market shares as well as the (absence of) relationship between the origin of the company, where it sells the goods, and the price it can command.

Assume that a pharmaceutical company sells monopolistically in three countries a product which it produces at constant marginal cost $c$ (the monopoly occurs because it holds a valid patent). Demands at the Low $(L)$, Middle $(M)$ and High $(H)$ (regulation) countries are given by:

$$
q_{H}=a-b p_{H} ; q_{M}=A-B p_{M}, q_{L}=A-B p_{L},
$$

The constants $a$ and $A$ are increasing in the quality of the good. The assumption that demands in the $M$ and $L$ countries are equal is taken for notational convenience. No substantive result changes for this reason. ${ }^{8}$

The prices are determined through the following game. The government of the $H$ country pursues a price-control policy. It unilaterally sets the maximum price at which the company can sell the product in country $H, \bar{p}_{H}$. The firm can choose between selling in that country, in which case it must choose a price $p_{H} \leq \bar{p}_{H}$ or not to sell the good at all. In the $M$ country the regulation is of the (external) reference price type, that is, $p_{M} \leq \lambda p_{H}+(1-\lambda) p_{L} \cdot{ }^{9}$ We further assume that countries $L, M$ and $H$ are such that $a / b \leq A / B$, that is, the monopolistic price is higher in $L$ or $M$ than in $H$. This means that the reference price constraint is always binding, and $p_{M}=\lambda p_{H}+(1-\lambda) p_{L}$.

Given that the price in unconstrained in $L$ (and assuming the absence of parallel imports that allow price discrimination across countries) the company sets the price $p_{L}$ equal to its monopolistic value. Then

$$
p_{L}^{*}=\frac{A}{2 B}+\frac{c}{2}
$$

\footnotetext{
${ }^{8} \mathrm{~A}$ minor change is that with $M$ and $L$ demands different, one could have a non-binding reference price constraints in $M$ if the $L$ country had a sufficiently larger size.

${ }^{9}$ The weight of different countries in the formula $(\lambda)$ is important for the quantitative aspects, but not for qualitative ones. For example, one can easily encompass a reference price formula that only puts weight on the lowest price by making $\lambda$ close to 1 since, as we shall see, $p_{H}$ is the lowest price. Alternatively, if the formula puts weight in proportion to market size, $\lambda$ could be close to zero when, as it often happens in reality, the largest country is $L$.
} 
In order to solve for the rest of the prices, let's assume first the company producing the good does not have headquarters at $H$. The regulator sets prices so that consumer surplus is maximized, and thus, it sets the minimum price consistent with the firm selling in $H$. Thus, the problem with the firm headquartered at $F=L$ is:

$$
\begin{aligned}
& \max _{p} \frac{1}{2}(a-b p)\left(\frac{a}{b}-p\right) \\
& \text { subject to } F(p) \doteq(p-c)(a-b p) \\
& +\left(\lambda p+(1-\lambda) p_{L}^{*}-c\right)\left(A-B\left(\lambda p+(1-\lambda) p_{L}^{*}\right)\right)+\pi_{L}^{*}-\pi_{M L}^{*} \geq 0
\end{aligned}
$$

where $\pi_{L}^{*}$ are the monopoly profits at $L$ and $\pi_{M L}^{*}$ is the monopoly profit of selling only at $M$ and $L$ (the prices at $L$ are obviously unaffected by whether the product is sold at $H$ or not). When selling only in $M$ and $L$ the reference price formula is irrelevant, since monopolistic prices are equal in $M$ and $L$. Thus,

$$
\pi_{M L}^{*}-\pi_{L}^{*}=\left(A-B\left(\frac{A}{2 B}+\frac{c}{2}\right)\right)\left(\frac{A}{2 B}-\frac{c}{2}\right)=\frac{(A-c B)^{2}}{4 B}=\pi_{L}^{*}
$$

Notice that since the objective function is decreasing in $p$, the optimal choice of $L$ 's regulator is to set the minimal price consistent with participation. Since

$$
\begin{aligned}
F\left(p_{L}^{*}\right) & =\left(p_{L}^{*}-c\right)\left(a-b p_{L}^{*}+A-B\left(\lambda p_{L}^{*}+(1-\lambda) p_{L}^{*}\right)\right)+\pi_{L}^{*}-\pi_{M L}^{*} \\
& =\left(p_{L}^{*}-c\right)\left(a-b p_{L}^{*}\right)+\left(p_{L}^{*}-c\right)\left(A-B p_{L}^{*}\right)-\pi_{L}^{*} \\
& =\left(p_{L}^{*}-c\right)\left(a-b p_{L}^{*}\right)+\pi_{L}^{*}-\pi_{L}^{*} \geq 0
\end{aligned}
$$

and

$$
F(0)=(0-c)(a-b 0)+\left(\lambda 0+(1-\lambda) p_{L}^{*}-c\right)\left(A-B\left(\lambda 0+(1-\lambda) p_{L}^{*}\right)\right)-\pi_{L}^{*}<0
$$

then there exists $p_{H}^{*}$, such that $F\left(p_{L}^{*}\right)=0$ and

$$
0<p_{H}^{*} \leq p_{L}^{*}
$$

and thus

$$
0<p_{H}^{*}<p_{M}^{*}=\lambda p_{H}^{*}+(1-\lambda) p_{L}^{*}<p_{L}^{*}
$$

Moreover

$p_{H}^{*}=\frac{K}{2\left(b+B \lambda^{2}\right)}-\frac{\sqrt{\tilde{K}^{2}-4\left(b+B \lambda^{2}\right)\left(c a+\left(c-(1-\lambda) p_{L}^{*}\right)\left(A-B(1-\lambda) p_{L}^{*}\right)+\pi_{L}^{*}\right)}}{2\left(b+B \lambda^{2}\right)}$ where $K=a+\lambda A-2 B \lambda(1-\lambda) p_{L}^{*}+c(b+B \lambda)$. In order to gain some intuition let $c=0$ and $B=b$. Then $p_{L}^{*}=A / 2 b$ and 


$$
\begin{aligned}
p_{H}^{*} & =\frac{\tilde{K}}{2 b\left(1+\lambda^{2}\right)}-\frac{\sqrt{\tilde{K}^{2}-4 b\left(1+\lambda^{2}\right)\left(-(1-\lambda) A / 2 b(A-b(1-\lambda) A / 2 b)+A^{2} / 4 b\right)}}{2 b\left(1+\lambda^{2}\right)} \\
& =\frac{a+\lambda^{2} A-\sqrt{\left(a+\lambda^{2} A\right)^{2}-\left(1+\lambda^{2}\right) \lambda^{2} A^{2}}}{2 b\left(1+\lambda^{2}\right)}
\end{aligned}
$$

where $\tilde{K}=a+\lambda A-2 b \lambda(1-\lambda) A / 2 b$. Notice that $p_{H}^{*}$ from (2) can fail to be well defined when

$$
\left(a+\lambda^{2} A\right)^{2}-\left(1+\lambda^{2}\right) \lambda^{2} A^{2}<0
$$

This can easily happen for $a$ small. This simply reflects the fact that for $a$ small we have a corner solution with $p_{H}^{*}=p_{L}^{*}$ since the demand for country $H$ is zero when $p=p_{L}^{*}$ and the only way to satisfy the equation in case $F(p)=0$ is with $p=p_{L}^{*}$. An economic way to interpret this finding is noticing that if country $H$ is too small, it cannot force the company to lower prices, since it always has the option to sell only in countries $M$ and $L$ and obtain a much higher price. In a sense, the reference price constraint in country $M$ protects the firm from lowering its price too much in country $H$.

On the other hand, if $a$ is very high relative to $A$, or if $\lambda$ is close to zero, then $p_{H}^{*}$ is close to zero, as the reference price constraint is not a good enough protection against the high regulatory environment of country $H$, either because $H$ is a large country and thus an important market, or because it is not too important in providing a reference for country $M$.

Finally, notice that when $b$ is large, prices are low, are closer together between the different countries. Since $b$ is closely related to elasticity of price sensitivity, one can interpret a high $b$ as an indicator that there are more substitutes or that the market is more competitive. This would typically happen for more mature products.

If the company has headquarters in the $H$ country, the regulator sets the price to maximize consumer surplus at $H$, plus firms profits. Thus, the price in country $H$ is completely determined by the regulator, by solving the following program:

$$
\begin{array}{ll}
\max _{p} & \frac{1}{2}(a-b p)\left(\frac{a}{b}-p\right)+(p-c)(a-b p)+\left(\lambda p+(1-\lambda) p_{L}^{*}-c\right)\left(A-B\left(\lambda p+(1-\lambda) p_{L}^{*}\right)\right)+\pi_{L}^{*} \\
& \text { subject to } \\
F(p) \quad \doteq(p-c)(a-b p)+\left(\lambda p+(1-\lambda) p_{L}^{*}-c\right)\left(A-B\left(\lambda p+(1-\lambda) p_{L}^{*}\right)\right)+\pi_{L}^{*}-\pi_{M L}^{*} \geq 0
\end{array}
$$

We solve the problem both with and without the constraint and then show when is the constraint binding at the optimum. The price $p$ that solves the problem without the constraint is 


$$
p_{H}^{* *}=\frac{\lambda A-2 B \lambda(1-\lambda) p_{L}^{*}+c(b+\lambda B)}{b+2 \lambda^{2} B}
$$

There is also $p_{H}^{*}$, which is the price that solves the constrained problem. Notice that $p_{H}^{*}$, is also the price that solves the problem when the firm does not have headquarters in $H$. Thus, when $p_{H}^{* *} / p_{H}^{*}>1$, the price for the local $H$ multinational would be higher than the price of an equivalent product from a foreign (to $H$ ) multinational. Again, in order to understand better when is the case that $p_{H}^{* *} / p_{H}^{*}>1$, let's assume that $c=0$ and $B=b$. Then $p_{L}^{*}=A / 2 b$ and

$$
\begin{gathered}
p_{H}^{* *}=\frac{\lambda A-2 b \lambda(1-\lambda) A / 2 b}{b\left(1+2 \lambda^{2}\right)}=\frac{\lambda^{2} A}{b\left(1+2 \lambda^{2}\right)} \\
p_{H}^{*}=\frac{a+\lambda^{2} A-\sqrt{\left(a+\lambda^{2} A\right)^{2}-\left(1+\lambda^{2}\right) \lambda^{2} A^{2}}}{2 b\left(1+\lambda^{2}\right)}
\end{gathered}
$$

Let $a / A=\delta$, then

$$
\frac{p_{H}^{* *}}{p_{H}^{*}}=\frac{1+2 \lambda^{2}}{2+2 \lambda^{2}} \frac{\lambda^{2}}{\delta+\lambda^{2}-\sqrt{\left(\delta+\lambda^{2}\right)^{2}-\left(1+\lambda^{2}\right) \lambda^{2}}}
$$

so when, for example $\lambda$ is close to 1 (i.e. the $H$ country is important in the reference price formula), and the highly regulated country is not too small (i.e. $\delta>0.71$ ), then $p_{H}^{* *} / p_{H}^{*}>1$. This means a firm from the highly regulated country $H$, but also important in the reference formula, cannot set higher prices than a foreign firm.

We can thus summarize a number of predictions from this simple model.

1. Prices from highly regulated countries will be higher than those of less regulated countries.

2. Reference pricing can provide a measure of protection against small but highly regulating countries.

3. The price differential of regulated countries will be smaller for products that are more mature or have higher substitutes.

4. Large regulating countries will provide a price premium for firms headquartered in their own country, however small but heavily regulated countries cannot influence substantially the prices in favor of the local multinationals. 


\section{Econometric specification}

In the previous section we have shown that the equilibrium price for product $i$ of firm $f$ in market $k$ and country $j, p_{i f k j}^{\prime}$, can be represented as a function of competitors' pricing strategies, quality variables and other factors, summarized in the function $A_{i f k j}^{*}$. Taking this into account, we consider the following log-linear specification:

$$
\log \left(p_{i f k j t}^{\prime}\right)=\alpha+A_{i f k j t}^{*}+v_{i f k j t}
$$

where $t$ denotes time, and $v$ denotes an error term, and $\alpha$ is a parameter. We further consider that

$$
A_{i f k j t}^{*}=X_{i f k j t}^{\prime} \beta+Z_{i j}^{\prime} \gamma+\eta_{r}+\eta_{j}+d_{t}
$$

where $X$ and $Z$ are vectors of respectively time-variant and time-invariant variables that potentially affect equilibrium prices, and $\beta$ and $\gamma$ are the corresponding vectors of parameters. The term $\eta_{r}$ represents a specific effect, where $r$ is (depending on the specification) either $i, f$, or, $k ; \eta_{j}$ is a country specific effect, and $d_{t}$ is a time specific factor. After replacing these expressions in the above equation we obtain:

$$
\log \left(p_{i f k j t}^{\prime}\right)=\alpha+X_{i f k j t}^{\prime} \beta+Z_{i}^{\prime} \gamma+\eta_{r}++\eta_{j}+d_{t}+v_{i f k j t}
$$

Note that when $r=i$, both the effect of $Z_{i j}$ and $\eta_{j}$ are absorbed by the individual effects and, consequently, they are not directly identifiable. ${ }^{10}$ Since we have a genuine interest in some time-invariant factors, we follow a two-stage procedure to estimate them (Mundlak, 1978): we first estimate the above 1st stage equation and obtain an estimate of $\eta_{i}$, say $\hat{\eta}_{i}$, and then, in a second stage, we regress $\hat{\eta}_{i}$ against the time invariant factors. That is we estimate the 2nd stage equation:

$$
\hat{\eta}_{i}=Z_{i}^{\prime} \gamma+\eta_{f}+\eta_{k}+\eta_{j}+u_{i}
$$

where $u_{i}$ is an error term and $\eta_{k}, \eta_{f}$, and $\eta_{j}$ control for market (or molecule), firm and country specific effects, respectively. Depending on the exact assumption about them, we follow one estimation strategy or another. For example, in case we assume they are random and uncorrelated with the variables in $Z$, then an LS estimate of the above equation identifies the parameters of the model. Alternatively, we can follow a conditional approach and use an LSDV estimator controlling either $\eta_{k}, \eta_{f}$ or $\eta_{j}$ or all three terms altogether. We shall explore some of these possibilities in data.

\footnotetext{
${ }^{10}$ Note also that $\eta_{j}$ is also not identifiable when the sample is restricted to a single country.
} 
An alternative strategy to identify the effect of the $Z$ variables is to assume that the product specific effects $\left(\eta_{i}\right)$ are well represented by the combination of market effects, say $\eta_{k}$ (or, alternatively corporation effects, say $\eta_{f}$ ) and the $Z_{i j}^{\prime} \gamma$ component. Note that, in this particular case, the effect of the variables in $Z$ can be identified in just one step.

We carry the analysis at two levels: country by country (25 countries) and pooling the data for all the countries. Note that in the latter case the country specific effects are fully identifiable. Since the number of markets and number of product varies across countries, we check the robustness of the results to the variation in two complementary dimensions: the number of countries in which the corporation to which the product belongs is present (for example: $1+, 10+, 20+, 25$ ), and the number of countries in which a given molecule is present (for example: $1+, 10+, 20+, 25$ ). We also present results when restricting the sample to single molecules, and when restricting it to products for which the molecule and the corporation is present in all the countries of the sample.

Regarding the estimation methods, we estimate equations (3 and 4) using a Within Groups panel data method. In the first stage, we control for time-invariant heterogeneity across product, while in the second we control for this heterogeneity across molecules. In order to avoid potential endogeneity problems of some variables, we follow an IV approach and lag all the time-varying (potentially endogenous) covariates in the model.

\section{Data, variables and specification}

We use a multi-country and multi-product data set from the IMS MIDAS international database for the period 1998-2003 ${ }^{11}$. This dataset encompasses a large number of countries including the top ten in terms of expenditure, as well as medium size and small countries (see Table 1 for a list of countries and summary statistics). It also includes a large number of groups or anatomic classifications, and allows to study the price variation across countries which differ in terms of both regulatory regimes and industrial structure. Many corporations supply drugs in several of these markets that can be defined at different levels of disaggregation. In the current study we regard the 4-digit Anatomic therapeutical classification (ATC4) as a market, but it would be desirable to contrast our results using alternative levels of disaggregation. ${ }^{12}$ Table 2 presents the distribution of corporations depending on the number of markets supplied, and Table 3 presents the distribution of

\footnotetext{
${ }^{11}$ Our data includes information from the $4^{\text {th }}$ quarter of each year, except for 2003, for which the information is provided for the $2^{\text {nd }}$ quarter.

${ }^{12}$ The ATC code was not provided in the original data supplied from IMS. Fortunately we obtained an additional sample from IMS Spain which helped us to recover the ATC for the rest of the countries. We managed to match practically all the records in sample.
} 
molecule ages by countries.

\subsection{Variables and first stage and second stage specifications}

The dependent variable in our analysis, called Price, corresponds to sales revenue divided by the number of 'standard units' sold. Accordingly, when several formulations of the product co-exist in the market, this corresponds to a weighted average of the price per standard unit of all these alternative formulations. Nominal country specific quantities are converted to 2000 US $\$$.

Marginal costs are almost irrelevant in this industry. ${ }^{13}$ Accordingly, in our regression we use a hedonic approach and include quality and competition variables (see section A.1 of the appendix for a list of variables with definitions) to proxy the equilibrium price. Our controls can be classified in one of two categories: time-variant and time-invariant controls.

Our list of time variant controls or first stage controls includes: the firm's size in terms of sales in the country, Fsales, which is constructed as total corporation sales (excluding sales of the product under analysis) in each country. Firm's size is included in log form in order to give more weight two differences in small values than in large values and it is lagged one period in order to avoid endogeneity problems. The average global price of the molecule (excluding the product under consideration) or Globalprice. The variable \# generics represents the number of generic products in each market and country. New is a dummy variable equal to one if the product was launched in the previous year and zero otherwise.

Among the competition variables we include the Hirschmand-Herfindähl concentration index of the local firms (excluding the firm the product belongs to), HHI. We also include the market share of the corporation in the market, Mshare, and its square, since we would expect that a higher market share lead to higher prices. In order to capture differential effects between local and foreign firms we interact these variables with the local and local multinational dummies (to be defined later). Again both variables could be regarded as endogenous and we lag them one period. Finally, we construct two other share variables: the market share of all the national products in the market, Natshare, and the Berry index which measures the "importance" or degree of specialization of the corporation in the product considered.

Our list of time invariant controls starts with the Fquota, defined as the average firm quota in the country. Singlemol takes a value of one, if the product consists of a single

\footnotetext{
${ }^{13}$ See, e.g. Berndt, Cockburn and Griliches, 1996, Suslow, 1996, Berndt, Pindyck and Azoulay, 1999, and Cockburn and Anis, 2001.
} 
molecule, and zero otherwise. Molecule age, Molage, is the time elapsed since the molecule was launched to December 31, 2003. The age distribution of molecules and products is presented in Table 3. We also include to Censormol, which equals 1 if the product was launched before January 1, 1991 and zero otherwise; Censorlag, which equals one for products launched before January 1, 1991 and one otherwise. We also include Summol which counts the number of countries a given molecule is present. Therefore it can be interpreted as a proxy of diffusion of a molecule. We finally construct dummies controlling the type of firm: local, local-multinational and multinational, for respectively local-non multinational, local-multinational and non-local multinational firms. They are interacted with Fquota, Mshare as well as New.

Following Danzon and Furukawa (2003) suggestions, in the time variant pooled countries specification we control for differences between the countries with two variables: $F P C$ or fraction of public consumption in GDP, ${ }^{14}$ and GDPPCUSD or GDP per capita in 2000 US $\$$. Both of them are interacted with a set of regulatory dummies. We consider three levels of regulation (low, medium and high, respectively): ${ }^{15}$ (I) Australia, Czech Republic, Canada, Denmark, Finland, Germany, Hungary, The Netherlands, Norway, Poland, Sweden, Switzerland, UK, and the US; (II) Austria, Belgium, France, Japan, Greece, Portugal, Spain; (III) Argentina, Brazil, Egypt, Italy. ${ }^{16}$

For the regression analysis we use log transformations of Price, Fsales, Globalprice Molage, and Summol so we value more the differences in smaller than in larger values. In order to avoid potential simultaneity bias all the regressors are lagged one period except for those related to the age of the product, which by nature are predetermined (specially once we control for $N e w)$.

\section{Results and interpretation}

In this section we present the results from the empirical analysis. We begin with a review of the country-by-country results and continue with the pooled results (for all products

\footnotetext{
${ }^{14}$ Public consumption over GDP (fpc) can be considered a proxy of several variables that might have a direct impact on prices such as Insurance (which may affect positively prices as noted by Duggan and Scott-Morton), Bargaining power (which may have a negative effect on prices).

${ }^{15}$ See Table 1 for summary statistics for all the countries. The classification was done by sending the list of countries to three experts in health and pharmaceutical economics, prior to the statistical analysis of our data. We asked them for a classification of countries in the list in three groups. In the very few cases where the classification was not unanimous (no country was ever placed in three different categories), we ranked it according to the majority view.

${ }^{16}$ Note that our classification, for the top countries, in terms of expending, is similar to that employed in Danzon and Chao (2000a, 2000b).
} 
as well divided by anatomic therapeutical group).

\subsection{Country by country results}

In tables 4 to 6 we present the country-by-country results of the first (top panel in each table) and second stage (bottom panel) regressions for all the countries in sample. In all the first stage regressions we use a IV-FE estimator, and a standard LS estimator in all the second stage regressions. Likewise, in all cases we present results with the complete sample of products. [Detailed results with restricted subsamples -by either restricting the number of countries a given corporation ( $\mathrm{C}$ dimension), or a given molecule ( $\mathrm{M}$ dimension), is present- are available upon request.]

After controlling for product (and time) fixed effects, the explanatory power of time varying variables is very limited in practically all the countries, evidencing very little time-series variation in the data. Despite so, we still are able to identify some regularities across countries.

- Key findings in first stage country-specific regressions:

1. Both the market share of national products in the market the product belongs to, the concentration of local products, and the Berry index seem to have little effect on prices.

2. New products get a small premium in a number of countries. The largest premium is observed for the US (whose results are reported in the last column of table 6). The nationality of the product does not command a significant change on the premium for novel products with two notable exceptions: the case of Italy in which new products from exclusively local producers get an extra premium and Canada where new product from local multinationals also get an important premium.

3. Other things equal, the effect of firm size in prices is either non-significant or negative but small. The largest effects are found in Denmark and the US.

4. The number of generics in the molecule, significantly reduces the level of prices in a large number of countries. In this case the larger effect are found in Italy and Japan. For the US the effect of the number of generics is insignificant.

5. Global prices have very little independent effect, with the notable exceptions of Germany, Spain and the US.

- Key findings in second stage country-specific regressions: 
1. Other things equal, products from exclusively local corporations have lower prices in practically all the countries. In many countries this may be due, at least partially, to the fact that they are perceived of lower quality. The effect of being local multinational is less clear, since in a number of countries the effect is either insignificant or negative. Non-significant coefficients imply that local and foreign multinational are treated equally. This is the case of the US or Canada, among other countries. In fact, with the exception of France, in all countries with a significant pharmaceutical industry, both local and foreign multinational are treated equally. Apart of this, in a number of countries we find a significantly negative coefficient (France, Italy, and Sweden among other countries). However, in practically all cases the implicit coefficient lays in between of those for exclusively local corporations and foreign multinational firms. Thus large multinational conglomerates seem to receive a premium over small, local, producers.

2. With the exception of Poland, the single molecule effect is either non-significant or positive, specially in big pharmaceutical markets (notably Canada, Germany, Italy, Netherlands, Spain, Sweden, UK and the US).

3. In a large majority of countries the coefficient of the generic variable is significantly negative, with the notable exception of Canada. The largest negative effects are observed in Belgium, France, Norway, Hungary and the UK.

4. Finally, our proxy for diffusion of a molecule, summol, affects positively product prices in a large number of countries (Austria, Belgium, Brazil, Canada, Czech Rep., Egypt, France, Germany, Greece, Hungary, Japan, Poland, Portugal, Spain, Sweden, UK and the US.

Let us now turn to pooled results, which are expected to be very informative since the variation in data augments drastically.

\subsection{Pooled Results}

In tables 7 and 8 we respectively present the result of the first and second stage regressions when pooling the information of all countries in sample. In both tables columns (1) and (2) present respectively the all-products and single molecule first stage and second stage results. The rest of the columns in the aforementioned tables present the results when varying the number of countries a corporation is present (dimension $\mathrm{C}$ ) and the number of 
countries the molecule is present (dimension M). ${ }^{17}$ The exploration of the results in these two dimensions will help us to, firstly, check the sensitivity of the results to the sample employed, and, secondly, to better understand the underlining common characteristics of the problem. As in the previous section, in all the first stage regression, we use a IV-FE estimator (with product fixed effects) with clustered standard errors. Alternatively, in all the second stage regression we use a LS-FE estimator (with molecule fixed effect).

We obtain a number of interesting results in the first stage regressions.

1. Neither the share of local product or the degree of concentration affect strongly (in a quantitative sense) the prices. In fact the effect of the share of local product is even negative when we restrict the sample to products of corporation presents in many countries. Regardless of the dimension explored, the effect of the firm size is significantly negative, but small. The degree of specialization of the corporation seems to have a positive effect on prices as we move along the $\mathrm{C}$ dimension, but this is not confirmed when we move in the $\mathrm{M}$ dimension. Apart from this, the number of generics does not seem to have any systematic effect on prices.

2. As expected, new products get a premium which increases in the two dimensions explored. Interestingly, we find that new product launches on the part of local innovative firms receive a larger premium than other types of (multinational) firms. As we shall illustrate in the next section (see table 9) the finding is robust to the analysis by therapeutical class.

3. The effect of the global price is always positive and significant. The effect decreases when the number of countries the corporation is present increases and increases with the diffusion of the molecule. It is also interesting to note that the absence of a global price (or global reference, which means the product is innovative) increases significantly the price (above $1 / 3$ if we move in the $\mathrm{C}$ dimension, and above $1 / 2$ if we move in the molecule dimension).

4. Finally, the pooling strategy allows us to identify the effect of some aggregate variables, such us the fraction of public consumption in the GDP and the per capita GDP. After preliminary exploration of the date we interacted both variables with the level of regulation (from 1, low, to 3, high). For low regulated countries (REG1), the effect of both variables is positive and significant and increases in the two dimensions studied. In particular, other things equal, an increase of one percentage

\footnotetext{
${ }^{17}$ We present results when the sample is restricted to products which belong to corporation or molecules present in $1+$ (all sample), $10+$ or 25 countries. Results for other restricted samples are in line with the ones presented here and are available upon request.
} 
basis points in the fraction of public consumption in the GDP translates into a 1.2 and 2.0 percent increase in the price, depending on the specification. Note that the elasticity increases as we move in the $\mathrm{C}$ dimension and reduces in the $\mathrm{M}$ dimension. Of particular interest is the fact that the effect of the fraction of public consumption in the GDP decreases with the level of regulation. This is a reasonable result. FPC is a proxy for several variables that might have a direct impact on prices, such as: insurance, which affects positively prices, as pointed out by Duggan and Scott-Morton (2006); and bargaining power, which affects negatively prices. The insurance component may dominate for low regulated countries, whereas the bargaining element is also important in highly regulated countries.

Likewise, the price elasticity of the GDP per capita is very high, between 2.0 and 0.8 depending on the specification. In contrast with the result for the fraction of public consumption, the price elasticity of the GDP per capita reduces as we move in either the $\mathrm{C}$ or the $\mathrm{M}$ dimension. In medium and high regulated countries the effect of the fraction of public consumption in the GDP gets reduced significantly, except for those molecule that are present in all the countries. Alternatively, the effect of the GPD is significantly higher for both types of countries.

We now turn our attention to second stage regressions results.

1. Being a product from a exclusively-local corporation clearly reduces the price by approximately 15 per cent regardless of the dimension studied.

2. Alternatively, being a product from a local multinational has no clear effect on prices except for those product in which the corporation and the molecule is present in all countries (last column of Table 8). In this particular case the effect is sizeable and negative. Thus, in general local and international multinational corporations are treated equally.

3. We find that on average the price for generic products is between -0.15 and -0.20 percent lower than other prices. Again, the effect is larger when the sample is restricted to products of corporation and molecules present in all countries.

The analysis of country fixed effects, as reported in Table 8 and Figure 1 for selected cases, gives us a very interesting picture of the role of the regulation. First of all, price in developing countries (with the exception, in some cases, of Egypt) or very regulated (European) countries are lower than in less regulated countries, particularly lower than in the US. As we move to a more homogeneous sample in the $\mathrm{C}$ dimension the price gap 
is more evident. Alternatively, when we move in the $\mathrm{M}$ dimension (varying the number of countries a given molecule is present), the effect is less evident, even non-significant in some cases. The differences are more evident when we look to the last column of Table 8 (were the sample is restricted to products of corporations and molecules present in all countries, see also Figure 1 and Table A for a summary of differences): the average country effect for the very regulated countries is -4.80 , for the regulated ones -3.20 and for the low regulated countries -0.435 .

Within the group of less regulated countries (which includes the Northern, Eastern and some Central European countries plus Australia, Canada and the US) we can also document several interesting findings. Firstly, in the overall sample (or the sample of single molecules) there is little evidence than average prices are higher in the US than in other countries (particularly the Eastern European ones, but also other countries), since we find a number of cases for which the country fixed effect is positive. Note that this finding is in accordance with the results in Danzon and Chao (2000b) but obtained in a much more general sample both in terms of products and countries considered. Secondly, as we move in the $\mathrm{C}$ dimension, all the country specific effects decrease, that is, those positive are closer to zero or change sign to negative (this is the case of Canada, Germany, Switzerland and UK) and those negative turn out more negative, but the average differences with respect to the US level increase. Thirdly, when we move in the M dimension, the differences between countries decrease but not by a large amount. Thus, the US have a relatively lower price (compared to other developed countries) for products manufactured by multinationals, and a higher price with products that are "very common" (probably at a later stage in their life cycle). This is consistent with the explanation that the U.S., with her insistence in competition rather than regulation to contain prices, does well for goods where there can be competition (mostly off-patent not quite innovative goods). On the other hand, the other (mostly European) developed countries are successful at capping the prices of patented innovative goods, whereas they are less able to contain prices for products where competition could do a good job at restraining prices in the absence of regulation.

To finalize we would like to stress to cases: Canada and that of the Nordic countries. In the case of Canada, we do not detect any differences in average price level in the overall sample. As we restrict the sample to products from multinational (most likely branded) some differences in favor of the US appear, that is prices in the US case are higher. On the contrary, as we move in the diffusion dimension, price in the Canada turn out to be higher. The case of the Nordic countries (Denmark, Finland, Norway and Sweden, which are classified in the group of "low" regulated countries), whose associated coefficients all 
Figure 1: Country effects for selected models.
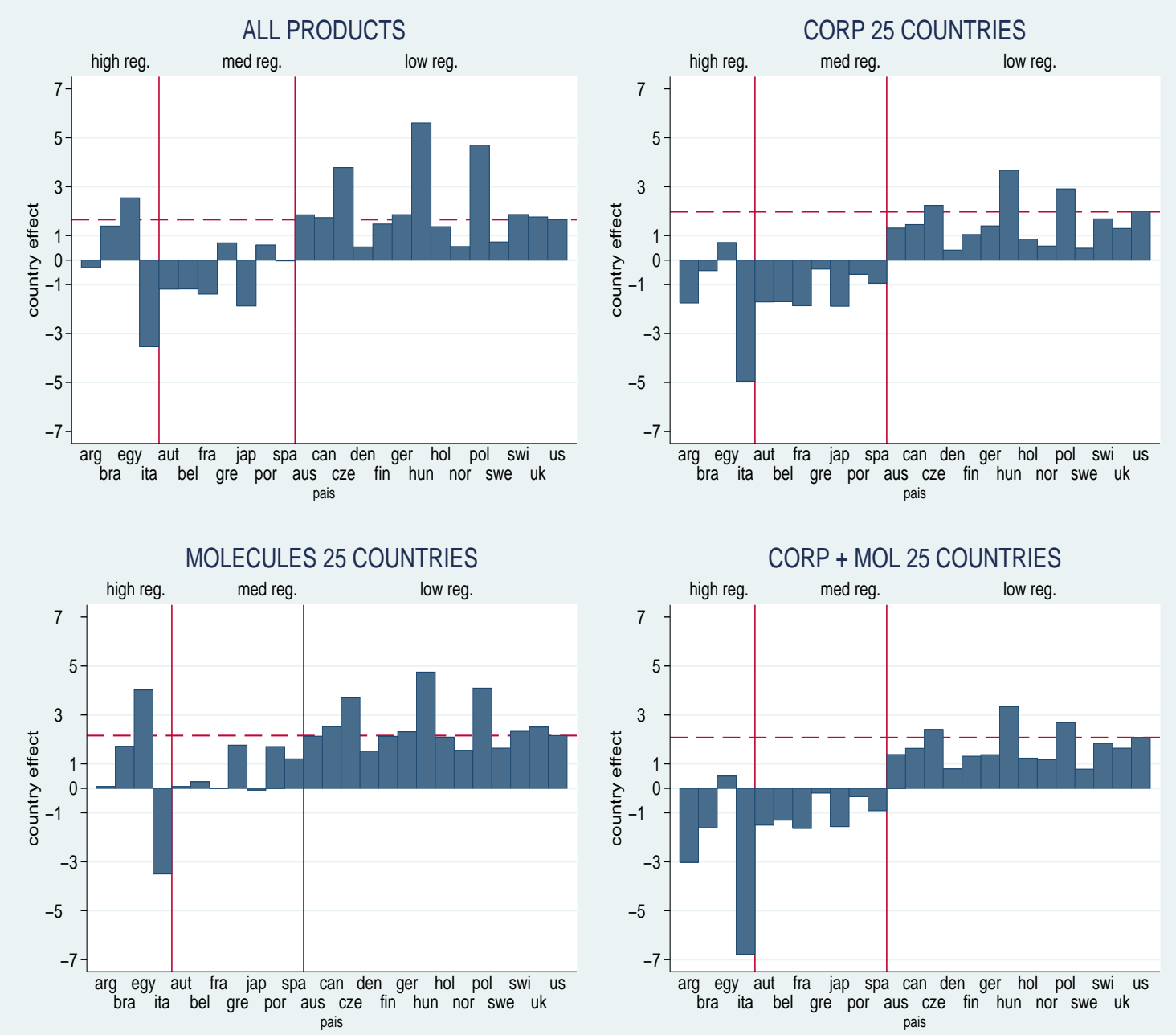

note: The dashed line marks the US country effect's level.

over Table 8 are significantly more negative than the rest of the coefficients for the group of low regulated countries, is also very interesting. This implies that Nordic countries manage to relatively achieve lower prices (see Table A for a summary) without a very strong regulation, suggesting an interesting avenue for future research.

Table A. Average differential of the country effect with respect to the US 


\begin{tabular}{lcrrr}
\hline Regulatory group & All & C 25P & M 25P & C+M 25P \\
\hline Very high & -1.63 & -3.60 & -1.58 & -4.80 \\
high & -2.28 & -3.29 & -1.44 & -3.14 \\
Spain & -1.69 & -2.94 & -1.37 & -2.99 \\
Low & 0.48 & -0.51 & 0.40 & -0.41 \\
Canada & 0.08 & -0.54 & 0.36 & -0.44 \\
Nordic countries & -0.83 & -1.37 & -0.45 & -1.06 \\
\hline
\end{tabular}

\subsection{Pooled results by therapeutical class}

In tables 9 and 10 we present the pooled sample results of the first and second stage regressions by therapeutical class (one-digit ATC classes). ${ }^{18}$ We only present results when the sample is not restricted in any dimension. As a rule, the analysis by therapeutical class gives a very similar qualitative picture than the pooled analysis we have performed in the previous section.

In the first stage regressions we obtain the following results.

1. The effect of the share of national product is in general non-significant with some important exceptions: class $\mathrm{C}$, for which it is negative, and classes $\mathrm{L}$ and $\mathrm{M}$ for which it is positive.

2. We confirm that once we control for product effects, the effect of the degree of concentration of national producers, the Berry index or firm size are not, as a rule, significant.

3. We also find that new products from exclusively local producers get a small premium for practically all therapeutical classes.

4. As found in previous studies the effect of the number of generics in the market is ambiguous since it is positive for classes $\mathrm{A}, \mathrm{N}$ and $\mathrm{R}$ and negative for classes $\mathrm{J}$ and M.

5. The results of the country level variables (GDP per capita and Public consumption to GDP ratio) are mostly in line with those reported in Table 7 . The elasticity of the price to the size of the public sector ranges from 1.4 (class $\mathrm{C}$ ) to 3.0 (class $\mathrm{H}$ ) and the elasticity of the GDP per capita ranges from 0.62 (class $\mathrm{H}$, non-significant) to 2.5 (class A). The effect of the size of the public sector reduces significantly as we

\footnotetext{
${ }^{18}$ We have analyzed twelve classes: see variable definition for a list and a description of classes.
} 
move to more regulation. On the contrary, the effect of the GDP per capita either does not vary with the level of regulation or it increases mildly.

The second stage results by therapeutical class clearly confirm that products from exclusively local firms are, other things equal, cheaper than products from multinational corporations. In contrast, we do not detect differences in any therapeutical class between local and foreign multinationals. The results for the rest of the quality variables are, as a rule, in accordance with expectations.

Results for country fixed effect (see Figure 2 for a summary) are also in line with those we discussed in the previous section. For a large number of therapeutical classes, the US is not, other things equal, the country with highest prices. In fact, average prices in Eastern (low regulated) European countries are, in a majority of groups, higher. More importantly, in some groups average prices in the UK, the nordic countries, Switzerland or, even Canada, are also higher. The estimated coefficients for very regulated countries are negative, which implies that regulation, other things equal, reduces average prices for practically all the anatomical therapeutical classes. The largest differences of regulated prices are observed for ATC classes $\mathrm{G}$ and $\mathrm{H}$ and the smaller for ATC classes A and R.

Results by ATC class also support the idea that price differences with respect to the US are higher for "branded" or innovative products and lower for mature or widely diffused molecules. In order to do so, we explore the correlation between the average difference with respect to the US of the country effect and the molecule age by regulatory group. We expect price differences with respect to the US to be lower for those classes in which the molecules are younger. The results confirm our expectations since the implied correlations are $0.44,0.28$ and 0.544 for regulatory groups low, medium and high, respectively.

\section{Conclusions}

In this paper we have investigated empirically the determinants of prices for pharmaceuticals. We have used a more extensive database than most previous studies, and we have used a large number of controls and paid a close attention to the empirical strategy and specification.

Our results do not support the view that the U.S. has higher prices than the rest of the countries in the sample. ${ }^{19}$ First, there is a group of "lightly regulated" countries whose prices are similar to those of the U.S. In addition, for molecules available in all the countries in the sample, more mature and widely diffused, the price differences are not large, even

\footnotetext{
${ }^{19}$ This confirms and extends prior work of Danzon and Chao (2000b), and contradicts the assertions contained in the U.S. Department of Commerce report (2004).
} 
Figure 2: Country effects by Therapeutical Class (1-digit ATC).
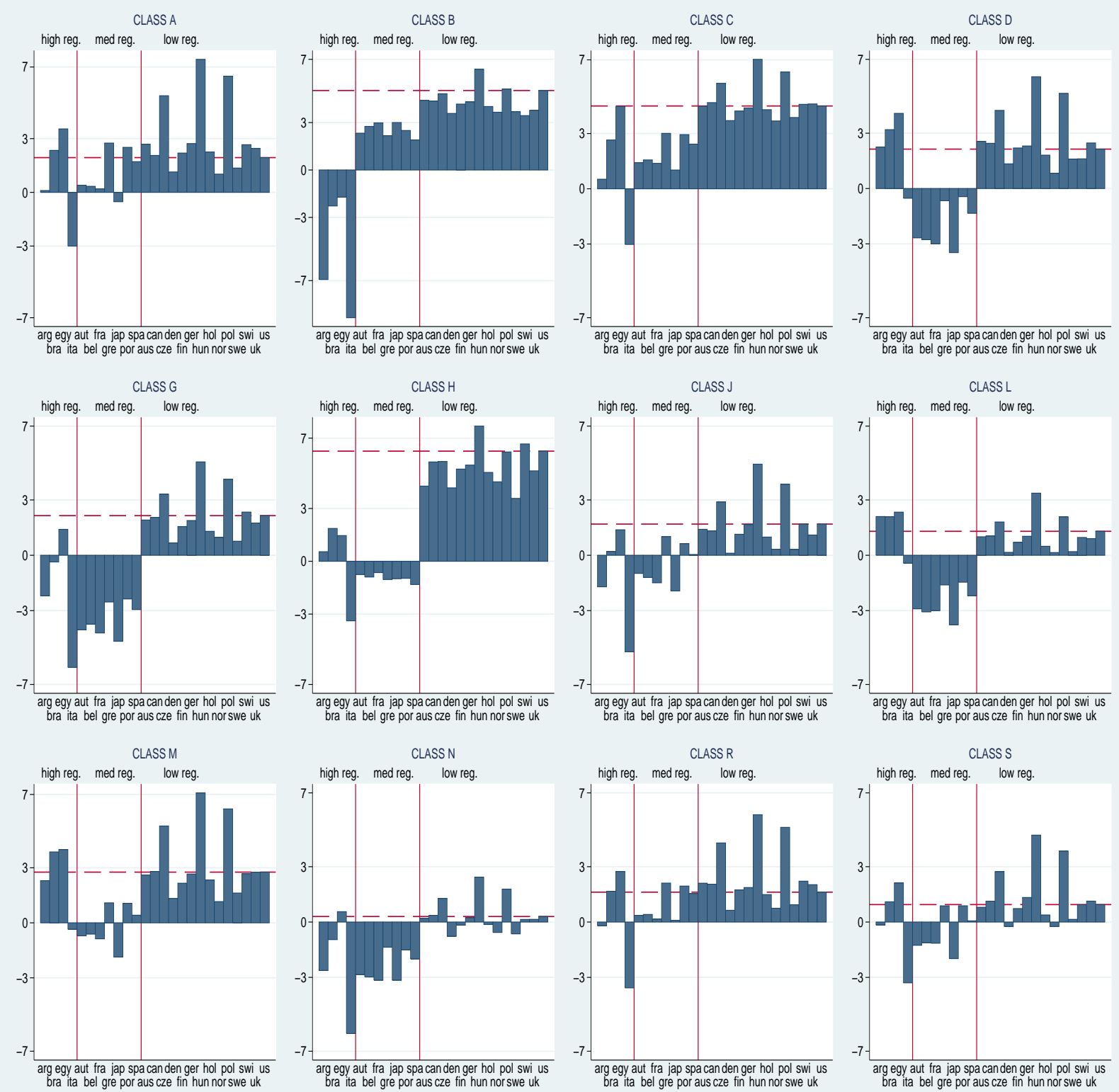

note: The dashed line marks the US country effect's level. 
with more highly regulated countries. An interesting avenue for further research is to explain how some countries with low regulation (such as the Nordic countries) achieve significantly lower average prices than others.

Another robust result, but somewhat contrary to conventional wisdom is that, in most countries, their own multinationals command no price premium with respect to foreign ones. Local, non-multinational firms tend to have lower prices than any multinational, and whether these multinationals are foreign or local does not affect prices in a statistically significant way. Our results, thus, do not support the view that the outcome of regulation conforms with the short-sighted best interest of local consumers. We do have evidence, on the other hand, that quality matters for prices, that firms exercise considerable market power, and that all multinational corporations obtain a price advantage.

We have constructed a theoretical model that accounts for all these findings simultaneously. We model a monopolistic product market, with three types of countries: those that do not regulate at all, those that regulate through (external) reference pricing and those that impose price caps. One interesting aspect of the model is that it shows that reference pricing confers a degree of protection against government intervention. Firms know that allowing prices to go too low in one country could lower prices in all others. They may prefer, thus, to exit completely one market rather than allowing it to spoil profits in all others. Knowing this, and since the product has indeed a value for voters, the regulator will refrain from driving too hard a bargain. Thus, there is a sense in which a reference price (or similar) policy in one country becomes a "commitment device" to avoid lowering price in another one. Its effects are akin to the low-price guarantees that have been widely studied in the industrial organization literature (Holt and Scheffman 1987, Arbatskaya, Hviid, Shaffer 2004) because of their anticompetitive implications.

In this paper we have thus argued that pharmaceutical prices do not show signs of being driven by pure rent-shifting motives from politicians. This does not mean that they are set in a way that maximizes welfare. Indeed, these prices have to balance the provision of long term incentives to innovation with the needs of present generations, something that is particularly difficult given the decentralized way in which regulations occur throughout the world. A necessary extension to the current work would be to ascertain empirically the relationship between current prices and socially efficient ones. This would, of course, require further theoretical work to determine a good benchmark (or a set of them) for socially efficient prices. 


\section{References}

[1] Arbatskaya, M., M. Hviid and G. Shaffer (2004), "On the Incidence and Variety of Low-Price Guarantees," Journal of Law and Economics, 47:307-332.

[2] Ballance, R., J. Pogány and H. Forstner (1992), The World's Pharmaceutical Industries, London, UK: Edward Elgar.

[3] Berndt, E.R., Cockburn, I., and Griliches, Z, 1996, "Pharmaceutical innovations and market dynamics: Tracking effects on price indexes for antidepressant drugs", Brookings Papers on Economic Activity: Microeconomics, pp.133-188.

[4] Berndt, E.R., Pindyck, R.S. and Azoulay, P., 1999, "Network effects and diffusion in pharmaceutical markets: antiulcer drugs", NBER Working Paper Series 7024.

[5] Caves, R., Whinston, M., and Hurwitz, M. (1991) "Patent Expiration, Entry, and Competition in the U.S. Pharmaceutical Industry," Brookings Papers.

[6] Cockburn, I. and A. Anis (2001), "Hedonic Analysis of Arthritis Drugs," in E. Berndt and D. Cutler (eds.) Medical Care Output and Productivity, University of Chicago Press, Chicago.

[7] Danzon, P.M. and L.W. Chao (2000a), "Does Regulation Drive Out Competition in Pharmaceutical Markets," Journal of Law and Economics, 43:311-357.

[8] Danzon, P.M. and L.W. Chao (2000b), "Cross-national price differences for pharmaceuticals: how large, and why?", Journal of Health Economics, 19, 159-195.

[9] Danzon, P.M. and M Furukawa (2003), "Prices and availability of Pharmaceuticals: evidence from nine countries" Health Affairs 521-536.

[10] Danzon, P.M. and M Furukawa (2006), "Prices and availability of Pharmaceuticals: an International Comparison, Health Affairs, 25: 1353-1362.

[11] Domínguez, B., J.J. Ganuza and G. Llobet (2006), "R\&D in the Pharmaceutical Industry: A World of Small Innovations," mimeo, CEMFI and Universitat Pompeu Fabra.

[12] Duggan, M., F. Scott-Morton (2006), ?The Distortionary Effects of Government Procurement: Evidence from Medicaid Prescription DrugPurchasing? Quarterly Journal of Economics, 121:1. 
[13] Ekelund M. and B. Persson (2003), "Pharmaceutical Pricing in a Regulated Country," The Review of Economics and Statistics, 85:298-306.

[14] Frank RG and Salkever DS (1992) "Pricing, Patent loss and the market for pharmaceuticals", Southern Economic Journal, 59(2), 165-179.

[15] Frank RG and Salkever DS (1997) "Generic entry and the pricing of pharmaceuticals", Journal of Economics and Management Strategy, 6(1), 75-90.

[16] Gambardella, A., L. Orsenigo and F. Pammolli (2000), Global Competitiveness in Pharmaceuticals: A European Perspective, Report prepared for the Enterprise Directorate-General of the European Union.

[17] Grabowsky, H. and J. Vernon, (1992) "Brand Loyalty, Entry and Price Competition in Pharmaceuticals after the 1984 Drug Act", Journal of Law and Economics,35, 331-350.

[18] Holt, C.A. and D.T. Scheffman (1987), "Facilitating Practices: The Effects of Advance Notice and Best-Price Policies," The RAND Journal of Economics, 18:187-197.

[19] Kyle, M (2007), "Price controls and entry strategy", Review of Economics and Statistics, 89(1), 88-99.

[20] Lu, Z.J. and W.S. Comanor (1998), "Strategic Pricing of New Pharmaceuticals," The Review of Economics and Statistics, 80:108-118.

[21] Mundlak Y (1978), "On the Pooling of Time Series and Cross-Section Data", Econometrica 46, 69-85.

[22] Motta M (2004), "Competition Policy: Theory and Practice," Cambridge: Cambridge University Press.

[23] Scherer, F.M. (2000), "The Pharmaceutical Industry," in A. Culyer and J. Newhouse, Eds. Handbook of Health Economics, Amsterdam: North Holland.

[24] Suslow VY (1996). "Measuring Quality Change in the Market for Anti-Ulcer Drugs," in RB Helms (ed.), Competitive Strategies in the Pharmaceutical Industry, Washington DC: AEI Press, 49-72.

[25] U.S. Department of Commerce (2004), "Pharmaceutical Price Controls in OECD Countries: Implications for U.S. Consumers, Pricing, Research and Development and Innovation," U.S. Department of Commerce, International Trade Administration, Washington D.C. 
[26] Wiggins S.N. and Maness R. (1994), "Price Competition in Pharmaceutical markets", unpublished manuscript, Texas A\&M University. 


\section{A Variable definition and descriptive statistics}

\section{A.1 Variable definition}

Variable

definition

Price

Sales revenue divided by the number of standard units sold (in logs)

Natshare The market share of all national products in the ATC4 market

HHI-local The Hirschmand-Herfindähl concentration index for national firms in the ATC4 market

fsales Firm sales in the country (in logs)

new

A dummy taking one if the product was first observed in the previous year

Berry index The Berry index measure the degree of specialization of the corporation

Ngen

Number of identified generics in the market

dum-GP n.a. Dummy of absence of a global price of reference

global price Average global price of the molecule in US real $\$$

local

A dummy taking one if the corporation is local-non multinational

localmulti A dummy taking one if the corporation is local but multinational

singlemol A dummy taking one if the product is not composite

lsummol Log of the number of market a molecule is present

generic A dummy taking one if the product is generic

Mshare Market share of the corporation the product belongs to in the ATC4 market

Fquota Average (in sample) firm quota of the firm in a given country

molage $\quad$ Time elapsed since the molecule was launched to December 31, 2003.

censormol A dummy taking one if the molecule was launched before January 1, 1991

censorlag A dummy taking one if the product was launched before January 1, 1991

fpc Fraction of public consumption in GDP (source: UN; in logs)

gdppcusd GDP per capita in 2000 US $\$$ (source: UN, in logs)

REG Level of regulation: 1 low, 2 medium, 3 high.

THERAPEUTICAL CLASSES (one-digit ATC)

A ALIMENTARY TRACT AND METABOLISM

B BLOOD AND BLOOD FORMING ORGANS

C CARDIOVASCULAR SYSTEM

D DERMATOLOGICALS

G GENITO URINARY SYSTEM AND SEX HORMONES

$\mathrm{H}$ SYSTEMIC HORMONAL PREPARATIONS, EXCL. SEX HORMONES AND INSUL

J ANTIINFECTIVES FOR SYSTEMIC USE

L ANTINEOPLASTIC AND IMMUNOMODULATING AGENTS

M MUSCULO-SKELETAL SYSTEM

$\mathrm{N} \quad$ NERVOUS SYSTEM

R RESPIRATORY SYSTEM

S SENSORY ORGANS 29 
Table 1: Summary statistics by country

\begin{tabular}{|c|c|c|c|c|c|c|c|c|c|c|c|c|c|}
\hline \multirow{3}{*}{ country } & \multirow{3}{*}{$\begin{array}{l}\# \text { of } \\
\text { corp }\end{array}$} & \multirow{3}{*}{$\begin{array}{l}\text { numbe } \\
\text { ATC4 }\end{array}$} & \multirow{3}{*}{$\begin{array}{l}\text { of ma } \\
\text { mol }\end{array}$} & \multirow{3}{*}{$\begin{array}{l}\text { arkets } \\
\text { prod. }\end{array}$} & \multirow{3}{*}{$\begin{array}{l}\text { prod } \\
/ \operatorname{mol}\end{array}$} & \multirow{2}{*}{\multicolumn{2}{|c|}{$\begin{array}{c}\text { ATC4 } \\
\text { HHI }\end{array}$}} & \multicolumn{3}{|c|}{ Average prices } & \multirow{3}{*}{$\begin{array}{l}\text { GDP } \\
\text { PC \$ }\end{array}$} & \multirow[t]{3}{*}{ FPC } & \multirow[t]{3}{*}{ REG } \\
\hline & & & & & & & & (1) & $(2)$ & (3) & & & \\
\hline & & & & & & mean & med & & & & & & \\
\hline Argentina & 250 & 273 & 1143 & 2892 & 2.5 & .237 & .158 & 14.7 & 1.92 & 1.20 & 7666 & .137 & 3 \\
\hline Brazil & 250 & 263 & 966 & 2711 & 2.8 & .254 & .140 & 2.66 & .762 & .362 & 3503 & .190 & 3 \\
\hline Egypt & 238 & 263 & 1038 & 1965 & 1.9 & .293 & .196 & .287 & .196 & .081 & 1467 & .097 & 3 \\
\hline Italy & 215 & 234 & 669 & 1821 & 2.7 & .286 & .203 & 5.48 & .293 & .220 & 18680 & .182 & 3 \\
\hline Austria & 207 & 234 & 716 & 1311 & 1.8 & .402 & .302 & 14.2 & .607 & .510 & 23503 & .192 & 2 \\
\hline Belgium & 183 & 200 & 508 & 962 & 1.9 & .396 & .297 & 4.63 & .207 & .174 & 22271 & .211 & 2 \\
\hline France & 214 & 235 & 721 & 1800 & 2.5 & .268 & .195 & 3.17 & .143 & .125 & 22065 & .232 & 2 \\
\hline Greece & 205 & 223 & 604 & 1216 & 2.0 & .401 & .329 & 9.83 & .956 & .588 & 10281 & .157 & 2 \\
\hline Japan & 181 & 213 & 530 & 1800 & 3.4 & .354 & .247 & 19.5 & .523 & .752 & 37361 & .164 & 2 \\
\hline Portugal & 172 & 187 & 446 & 875 & 2.0 & .379 & .286 & 1.20 & .113 & .069 & 10629 & .205 & 2 \\
\hline Spain & 220 & 225 & 640 & 1620 & 2.5 & .296 & .212 & 4.00 & .290 & .200 & 13785 & .175 & 2 \\
\hline Australia & 160 & 172 & 438 & 909 & 2.1 & .397 & .305 & 8.28 & .407 & .316 & 20315 & .179 & 1 \\
\hline Canada & 213 & 236 & 812 & 2397 & 3.0 & .246 & .153 & 5.66 & .244 & .203 & 23198 & .185 & 1 \\
\hline CzechRepublic & 239 & 264 & 803 & 1406 & 1.7 & .406 & .332 & 4.50 & .830 & .322 & 5426 & .220 & 1 \\
\hline Denmark & 197 & 222 & 653 & 1890 & 2.9 & .235 & .152 & 24.1 & .812 & .823 & 29730 & .252 & 1 \\
\hline Finland & 154 & 184 & 459 & 695 & 1.5 & .451 & .367 & 12.7 & .551 & .508 & 23161 & .206 & 1 \\
\hline Germany & 261 & 289 & 1489 & 5831 & 3.9 & .169 & .097 & 7.83 & .344 & .300 & 22730 & .189 & 1 \\
\hline Hungary & 188 & 205 & 550 & 891 & 1.6 & .411 & .333 & 5.47 & 1.17 & .430 & 4661 & .096 & 1 \\
\hline Nether & 146 & 172 & 404 & 1084 & 2.7 & .393 & .287 & 7.29 & .312 & .267 & 23314 & .226 & 1 \\
\hline Norway & 140 & 164 & 388 & 664 & 1.7 & .437 & .336 & 12.4 & .314 & .352 & 39484 & .191 & 1 \\
\hline Poland & 221 & 239 & 678 & 1259 & 1.8 & .412 & .314 & 6.89 & 1.60 & .694 & 4307 & .189 & 1 \\
\hline Sweden & 176 & 204 & 590 & 1431 & 2.4 & .306 & .226 & 28.8 & 1.06 & 1.17 & 27050 & .265 & 1 \\
\hline Switz & 228 & 252 & 828 & 1336 & 1.6 & .360 & .279 & 9.67 & .281 & .339 & 34330 & .111 & 1 \\
\hline UK & 189 & 209 & 585 & 1054 & 1.8 & .426 & .342 & 6.97 & .284 & .282 & 24525 & .186 & 1 \\
\hline US & 264 & 302 & 1397 & 5785 & 4.1 & .194 & .115 & 16.0 & .468 & .470 & 34262 & .143 & 1 \\
\hline
\end{tabular}

Notes: The sample is restricted to products with positive consumption in the 1998-2003.

(1): Average prices; (2) Av of prices relative to per capita GDP (in 2000 US \$); (3) Price average relative to per capita GDP (in 2000 US $\$$ but corrected for PPP). FPC: public consumption to GDP ratio; REG: Regulatory level: a lower number indicates less regulation. 
Table 2: Distribution of the number of molecules of the corporations by country

\begin{tabular}{lrrrrrrr} 
country & 1 & $2-4$ & $5-9$ & $10-14$ & $15-20$ & $21+$ & Total \\
\hline Argentina & 37 & 51 & 32 & 20 & 13 & 28 & 181 \\
Australia & 19 & 12 & 12 & 7 & 2 & 9 & 61 \\
Austria & 76 & 34 & 20 & 4 & 5 & 11 & 150 \\
Belgium & 19 & 32 & 21 & 7 & 2 & 8 & 89 \\
Brazil & 32 & 33 & 27 & 17 & 14 & 22 & 145 \\
Canada & 46 & 34 & 18 & 9 & 13 & 22 & 142 \\
CzechRepublic & 39 & 39 & 25 & 12 & 9 & 9 & 133 \\
Denmark & 37 & 25 & 16 & 8 & 5 & 13 & 104 \\
Egypt & 68 & 41 & 10 & 9 & 10 & 16 & 154 \\
Finland & 46 & 19 & 13 & 9 & 3 & 6 & 96 \\
France & 47 & 40 & 21 & 5 & 5 & 12 & 130 \\
Germany & 128 & 128 & 54 & 27 & 17 & 31 & 385 \\
Greece & 60 & 43 & 27 & 16 & 7 & 3 & 156 \\
Hungary & 26 & 29 & 14 & 8 & 4 & 7 & 88 \\
Italy & 59 & 73 & 37 & 18 & 5 & 9 & 201 \\
Japan & 28 & 40 & 41 & 16 & 8 & 5 & 138 \\
Nether & 17 & 26 & 14 & 7 & 1 & 13 & 78 \\
Norway & 36 & 20 & 14 & 7 & 5 & 5 & 87 \\
Poland & 57 & 37 & 24 & 11 & 10 & 6 & 145 \\
Portugal & 25 & 33 & 34 & 8 & 2 & 5 & 107 \\
Spain & 35 & 44 & 38 & 16 & 7 & 13 & 153 \\
Sweden & 44 & 38 & 15 & 9 & 6 & 12 & 124 \\
Switz & 57 & 40 & 23 & 9 & 6 & 8 & 143 \\
UK & 47 & 45 & 16 & 9 & 7 & 8 & 132 \\
US & 189 & 146 & 76 & 22 & 23 & 60 & 516 \\
& & & & & & & \\
\hline
\end{tabular}


Table 3: Distribution of molecule age by country

\begin{tabular}{|c|c|c|c|c|c|c|c|}
\hline country & 1 & $1-2$ & $3-4$ & $4-7$ & $7-10$ & $11+$ & Total \\
\hline Argentina & 23 & 110 & 185 & 393 & 308 & 124 & 1143 \\
\hline Australia & 13 & 75 & 82 & 145 & 99 & 24 & 438 \\
\hline Austria & 11 & 109 & 126 & 251 & 145 & 74 & 716 \\
\hline Belgium & 18 & 97 & 117 & 154 & 84 & 38 & 508 \\
\hline Brazil & 32 & 146 & 179 & 296 & 202 & 111 & 966 \\
\hline Canada & 15 & 102 & 101 & 229 & 285 & 80 & 812 \\
\hline CzechRepublic & 20 & 107 & 105 & 259 & 198 & 114 & 803 \\
\hline Denmark & 15 & 81 & 93 & 230 & 168 & 66 & 653 \\
\hline Egypt & 51 & 213 & 205 & 278 & 227 & 64 & 1,038 \\
\hline Finland & 10 & 71 & 68 & 166 & 105 & 39 & 459 \\
\hline France & 23 & 86 & 123 & 268 & 137 & 84 & 721 \\
\hline Germany & 29 & 227 & 172 & 369 & 411 & 281 & 1,489 \\
\hline Greece & 14 & 133 & 97 & 192 & 103 & 65 & 604 \\
\hline Hungary & 9 & 93 & 90 & 184 & 122 & 52 & 550 \\
\hline Italy & 12 & 77 & 129 & 248 & 138 & 65 & 669 \\
\hline Japan & 4 & 82 & 106 & 151 & 136 & 51 & 530 \\
\hline Nether & 11 & 62 & 66 & 128 & 92 & 45 & 404 \\
\hline Norway & 6 & 73 & 84 & 132 & 67 & 26 & 388 \\
\hline Poland & 10 & 76 & 127 & 172 & 220 & 73 & 678 \\
\hline Portugal & 14 & 77 & 80 & 139 & 89 & 47 & 446 \\
\hline Spain & 19 & 104 & 110 & 215 & 124 & 68 & 640 \\
\hline Sweden & 6 & 80 & 128 & 209 & 125 & 42 & 590 \\
\hline Switz & 4 & 98 & 141 & 276 & 229 & 80 & 828 \\
\hline UK & 16 & 87 & 98 & 201 & 127 & 56 & 585 \\
\hline US & 13 & 171 & 205 & 391 & 360 & 257 & 1,397 \\
\hline
\end{tabular}


Table 4: Single country results (I): Argentina-Egypt. All products.

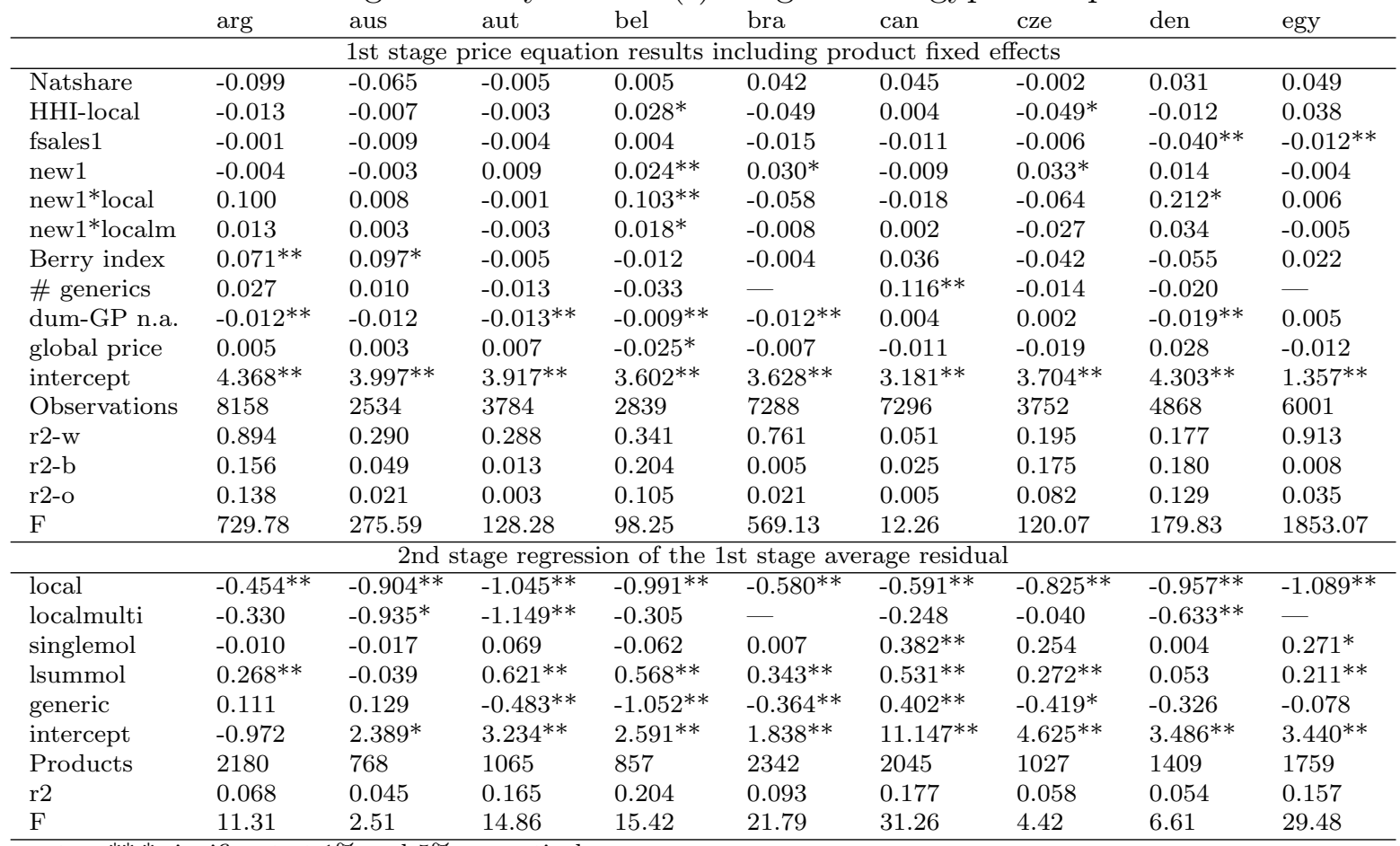

notes: $* * *$ significant at $1 \%$ and $5 \%$ respectively.

Clustered standard errors by corporation.

All regressors except those related to age are lagged one period.

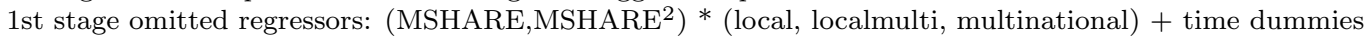

2sn stage omitted regressors: (FQUOTA, FQUOTA ${ }^{2}$ ) * (local, localmulti, multinational)+

2sn stage omitted regressors: CENSORLAG, CENSORMOL) 
Table 5: Single country results (II): Finland-The Netherlands. All products

\begin{tabular}{|c|c|c|c|c|c|c|c|c|}
\hline & fin & fra & ger & gre & hun & ita & jap & Net \\
\hline \multicolumn{9}{|c|}{ 1st stage price equation results including product fixed effects } \\
\hline Natshare & -0.072 & -0.053 & 0.008 & 0.007 & $-0.175^{* *}$ & 0.052 & -0.037 & 0.016 \\
\hline HHI-local & 0.006 & -0.005 & 0.016 & 0.013 & 0.053 & 0.023 & -0.008 & 0.010 \\
\hline fsales1 & 0.001 & -0.008 & -0.002 & 0.007 & -0.007 & -0.005 & -0.005 & $-0.010 *$ \\
\hline new1 & 0.022 & 0.010 & $0.016^{* *}$ & 0.014 & 0.012 & 0.015 & 0.015 & 0.003 \\
\hline new1*local & 0.122 & 0.117 & $0.090^{*}$ & -0.048 & -0.136 & 0.091 & -0.050 & 0.068 \\
\hline new1*localm & 0.027 & 0.016 & $0.024 * *$ & -0.005 & -0.028 & 0.013 & 0.010 & 0.010 \\
\hline Berry index & -0.016 & 0.037 & 0.002 & 0.015 & -0.033 & $0.060 * *$ & 0.096 & 0.131 \\
\hline \# generics & - & -0.002 & 0.004 & -0.011 & - & 0.002 & -0.012 & $-0.058^{*}$ \\
\hline dum-GP n.a. & $-0.009^{*}$ & -0.001 & $-0.003^{* *}$ & 0.005 & -0.031 & $-0.030^{* *}$ & $-0.041^{* *}$ & $-0.009^{*}$ \\
\hline global price & 0.031 & 0.003 & -0.003 & 0.047 & 0.006 & -0.007 & $0.028^{*}$ & 0.015 \\
\hline intercept & $4.146^{* *}$ & $3.141^{* *}$ & $3.300^{* *}$ & $4.062^{* *}$ & $3.645^{* *}$ & $3.891^{* *}$ & $4.117^{* *}$ & $4.579^{* *}$ \\
\hline Observations & 1969 & 5798 & 17336 & 3741 & 2676 & 5759 & 5340 & 2615 \\
\hline $\mathrm{r} 2-\mathrm{w}$ & 0.308 & 0.340 & 0.217 & 0.599 & 0.295 & 0.347 & 0.287 & 0.596 \\
\hline $\mathrm{r} 2-\mathrm{b}$ & 0.353 & 0.313 & 0.313 & 0.000 & 0.088 & 0.013 & 0.048 & 0.042 \\
\hline r2-o & 0.164 & 0.150 & 0.183 & 0.001 & 0.022 & 0.019 & 0.048 & 0.028 \\
\hline $\mathrm{F}$ & 96.68 & 218.84 & 329.86 & 573.90 & 261.79 & 91.30 & 77.05 & 373.06 \\
\hline \multicolumn{9}{|c|}{ 2nd stage regression of the 1st stage average residual } \\
\hline local & -0.261 & $-0.685^{* *}$ & -0.046 & $-1.031^{* *}$ & -0.377 & $-0.446^{* *}$ & $-1.038^{* *}$ & -0.028 \\
\hline localmulti & - & $-0.393^{* *}$ & -0.113 & -0.532 & - & $-0.413^{*}$ & 0.011 & 0.291 \\
\hline singlemol & -0.021 & -0.145 & $0.246 * *$ & $0.728 * *$ & -0.090 & $0.684^{* *}$ & -0.295 & $0.531^{* *}$ \\
\hline lsummol & -0.030 & $0.532 * *$ & $0.548^{* *}$ & $0.464^{* *}$ & $0.592^{* *}$ & 0.053 & $0.317^{* *}$ & 0.182 \\
\hline generic & $-0.834^{* *}$ & $-0.908 * *$ & $-0.689 * *$ & -0.282 & $-1.132^{* *}$ & $-0.388 * *$ & -0.252 & $-0.407^{*}$ \\
\hline intercept & -0.259 & $4.586^{* *}$ & $6.958^{* *}$ & $3.742^{* *}$ & $4.650^{* *}$ & 1.230 & $4.933^{* *}$ & $3.964^{* *}$ \\
\hline Products & 530 & 1654 & 4956 & 1066 & 686 & 1680 & 1509 & 858 \\
\hline $\mathrm{r} 2$ & 0.050 & 0.200 & 0.157 & 0.136 & 0.113 & 0.046 & 0.103 & 0.048 \\
\hline $\mathrm{F}$ & 2.49 & 29.33 & 65.88 & 11.83 & 7.80 & 5.73 & 12.23 & 3.01 \\
\hline
\end{tabular}

notes: $* *, *$ significant at $1 \%$ and $5 \%$ respectively.

Clustered standard errors by corporation.

All regressors except those related to age are lagged one period.

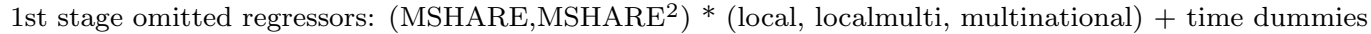

2sn stage omitted regressors: (FQUOTA, FQUOTA ${ }^{2}$ ) ${ }^{*}$ (local, localmulti, multinational) +

2sn stage omitted regressors: CENSORLAG, CENSORMOL) 
Table 6: Single country results (III): Norway-US. All products

\begin{tabular}{|c|c|c|c|c|c|c|c|c|}
\hline & nor & pol & por & spa & swe & swi & uk & us \\
\hline \multicolumn{9}{|c|}{ 1st stage price equation results including product fixed effects } \\
\hline Natshare & -0.077 & -0.072 & -0.004 & 0.054 & 0.062 & 0.008 & 0.033 & 0.047 \\
\hline HHI-local & $-0.056^{* *}$ & 0.008 & $0.023^{*}$ & 0.037 & 0.015 & 0.012 & 0.023 & 0.048 \\
\hline fsales1 & 0.011 & -0.000 & 0.006 & 0.005 & 0.005 & 0.002 & -0.010 & $-0.022^{* *}$ \\
\hline new1 & -0.016 & $0.028^{*}$ & 0.010 & $0.018^{*}$ & 0.001 & 0.009 & 0.010 & $0.085^{* *}$ \\
\hline new $1 *$ local & 0.016 & 0.117 & -0.004 & $0.129^{*}$ & 0.104 & 0.000 & 0.072 & $0.204^{* *}$ \\
\hline new1*localm & -0.001 & 0.025 & -0.009 & $0.023^{* *}$ & 0.018 & -0.001 & 0.005 & $0.041 * *$ \\
\hline Berry index & - & -0.031 & -0.011 & -0.017 & 0.005 & -0.035 & -0.011 & 0.021 \\
\hline \# generics & -0.003 & 0.005 & $-0.029^{*}$ & -0.017 & 0.002 & -0.023 & -0.026 & -0.041 \\
\hline dum-GP n.a. & -0.004 & -0.005 & -0.005 & $-0.005^{* *}$ & $-0.015^{* *}$ & -0.007 & -0.006 & -0.003 \\
\hline global price & 0.006 & -0.008 & -0.017 & 0.003 & 0.037 & -0.013 & $0.046^{* *}$ & 0.007 \\
\hline intercept & $4.623^{* *}$ & $3.477^{* *}$ & $3.801^{* *}$ & $3.461^{* *}$ & $4.574^{* *}$ & $3.440 * *$ & $4.172^{* *}$ & $3.307 * *$ \\
\hline Observations & 1631 & 3643 & 2619 & 5074 & 3840 & 4410 & 3072 & 15474 \\
\hline $\mathrm{r} 2-\mathrm{w}$ & 0.383 & 0.041 & 0.654 & 0.373 & 0.281 & 0.569 & 0.159 & 0.045 \\
\hline $\mathrm{r} 2-\mathrm{b}$ & 0.000 & 0.428 & 0.014 & 0.127 & 0.149 & 0.010 & 0.031 & 0.243 \\
\hline $\mathrm{r} 2-\mathrm{o}$ & 0.002 & 0.374 & 0.000 & 0.079 & 0.084 & 0.006 & 0.029 & 0.226 \\
\hline $\mathrm{F}$ & 159.11 & 10.74 & 663.01 & 253.57 & 124.38 & 323.45 & 21.62 & 5.77 \\
\hline \multicolumn{9}{|c|}{ 2nd stage regression of the 1 st stage average residual } \\
\hline local & 0.683 & $-0.645^{* *}$ & -0.009 & $-0.541^{* *}$ & $-0.901^{* *}$ & $-1.102^{* *}$ & $-1.012^{* *}$ & $-0.930 * *$ \\
\hline localmulti & 0.063 & $-0.839^{*}$ & $0.898^{*}$ & 0.100 & $-1.208^{* *}$ & -0.173 & -0.073 & 0.160 \\
\hline singlemol & 0.386 & $-0.513^{* *}$ & -0.124 & $0.280^{*}$ & $0.409^{*}$ & -0.086 & $0.439^{*}$ & $0.502^{* *}$ \\
\hline lsummol & -0.430 & $0.230^{*}$ & $0.548^{* *}$ & $0.359 * *$ & 0.040 & $0.612^{* *}$ & $0.285^{* *}$ & $0.176^{* *}$ \\
\hline generic & $-1.147^{* *}$ & $-0.800^{* *}$ & $-0.545^{* *}$ & $-0.382^{* *}$ & $-0.437^{*}$ & $-0.349^{*}$ & $-0.999 * *$ & $-0.524^{* *}$ \\
\hline intercept & $6.322^{* *}$ & 1.632 & 0.906 & $4.683^{* *}$ & $5.537 * *$ & $4.665^{* *}$ & $3.958^{* *}$ & $9.178^{* *}$ \\
\hline Product & 476 & 979 & 755 & 1475 & 1118 & 1159 & 867 & 4626 \\
\hline r2 & 0.106 & 0.079 & 0.095 & 0.105 & 0.060 & 0.179 & 0.139 & 0.179 \\
\hline $\mathrm{F}$ & 3.89 & 5.87 & 5.57 & 12.19 & 5.92 & 17.85 & 9.83 & 71.80 \\
\hline
\end{tabular}

notes: $* * *$ significant at $1 \%$ and $5 \%$ respectively.

Clustered standard errors by corporation.

All regressors except those related to age are lagged one period.

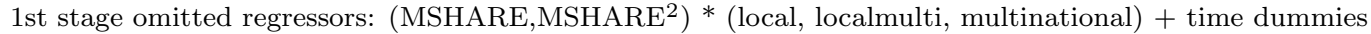

2sn stage omitted regressors: (FQUOTA, FQUOTA ${ }^{2}$ ) ${ }^{*}$ (local, localmulti, multinational)+

2sn stage omitted regressors: CENSORLAG, CENSORMOL) 


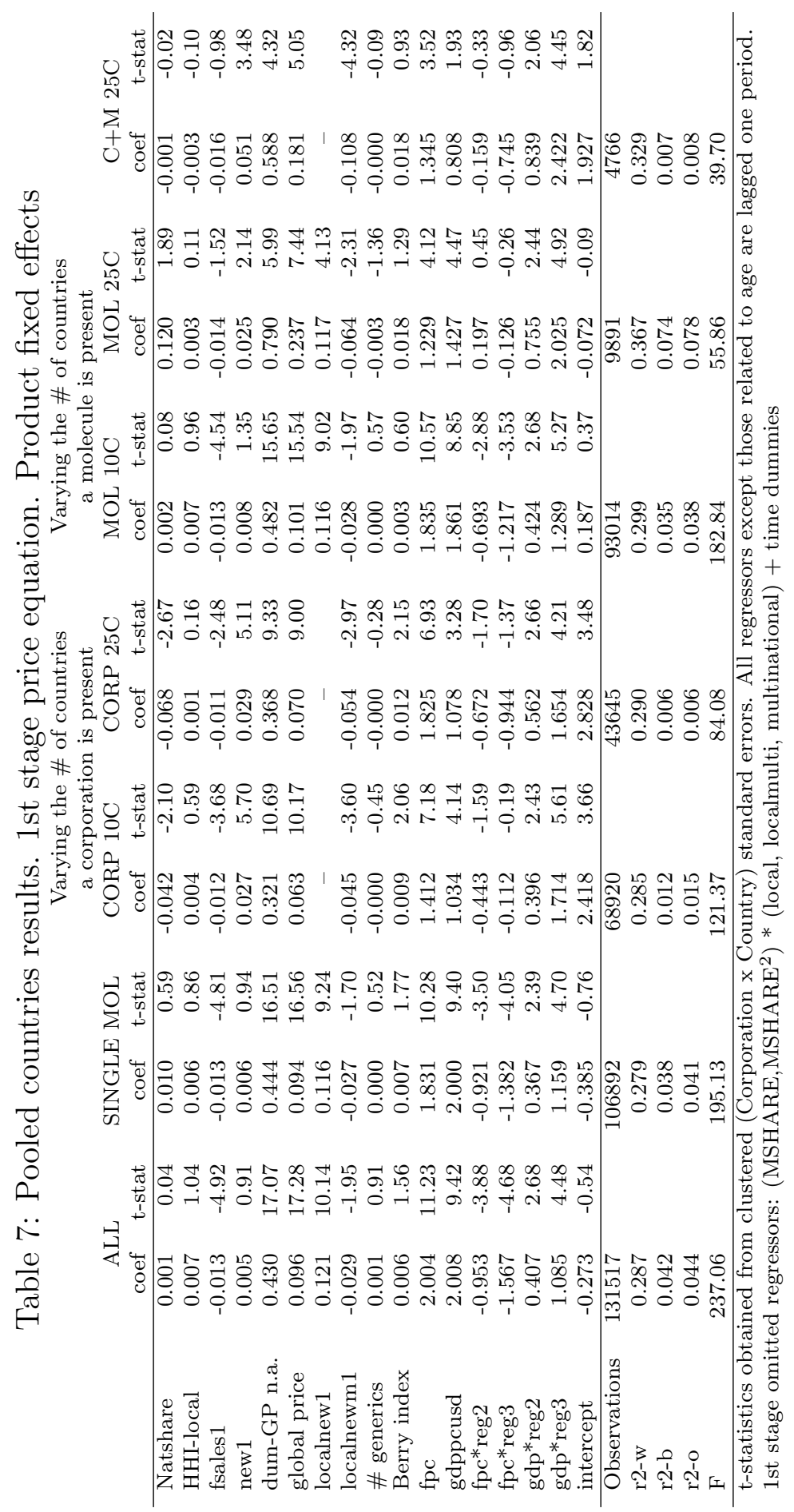




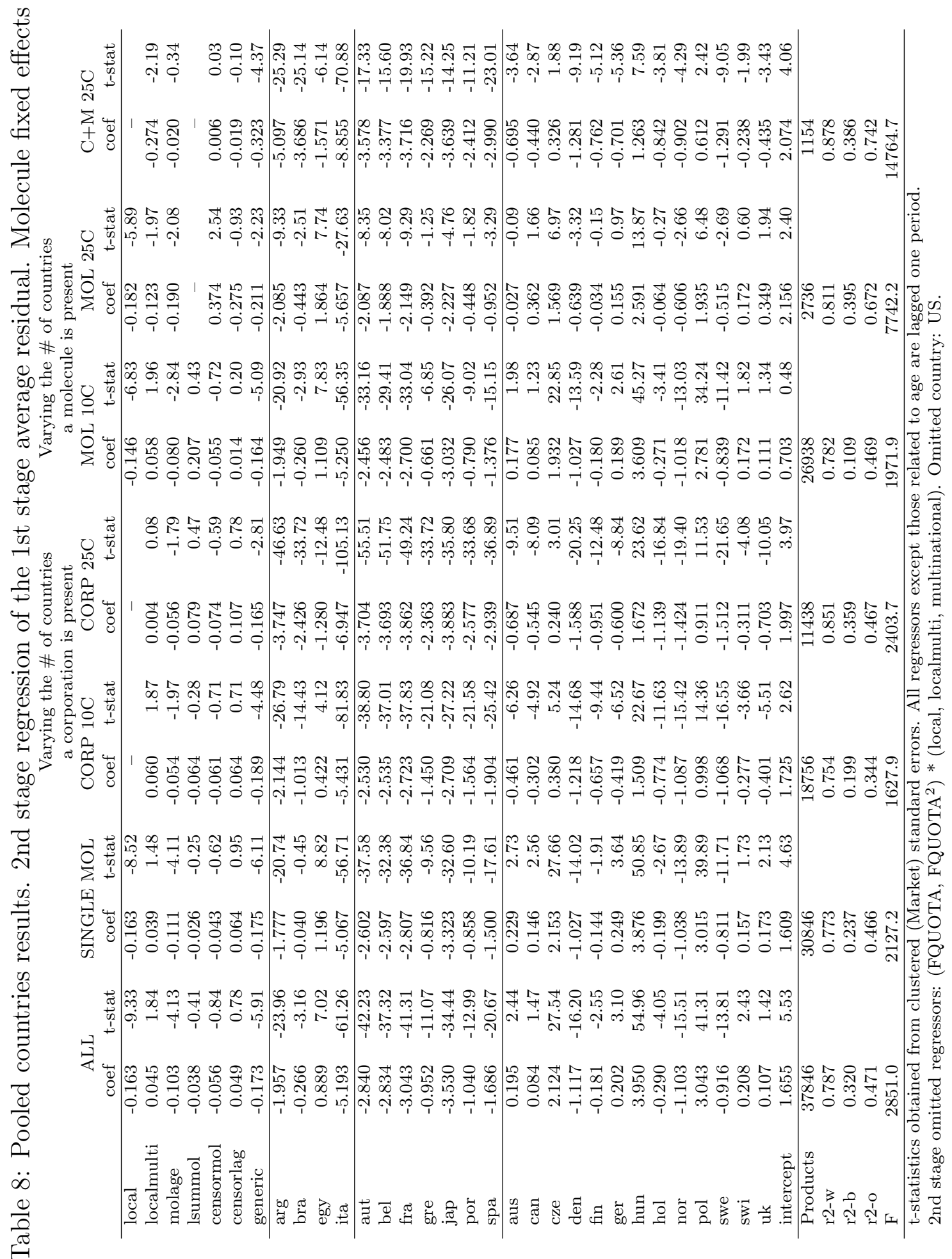




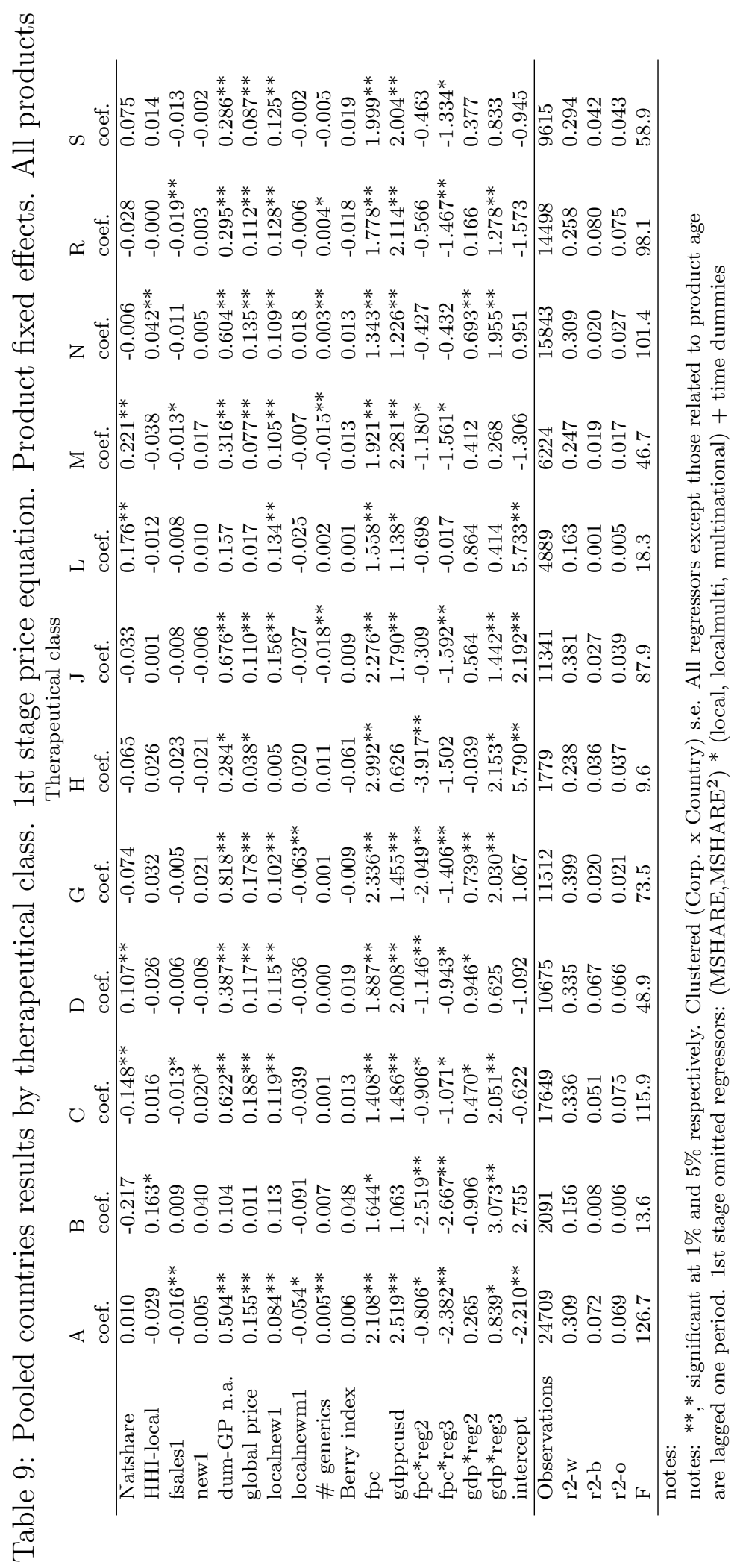




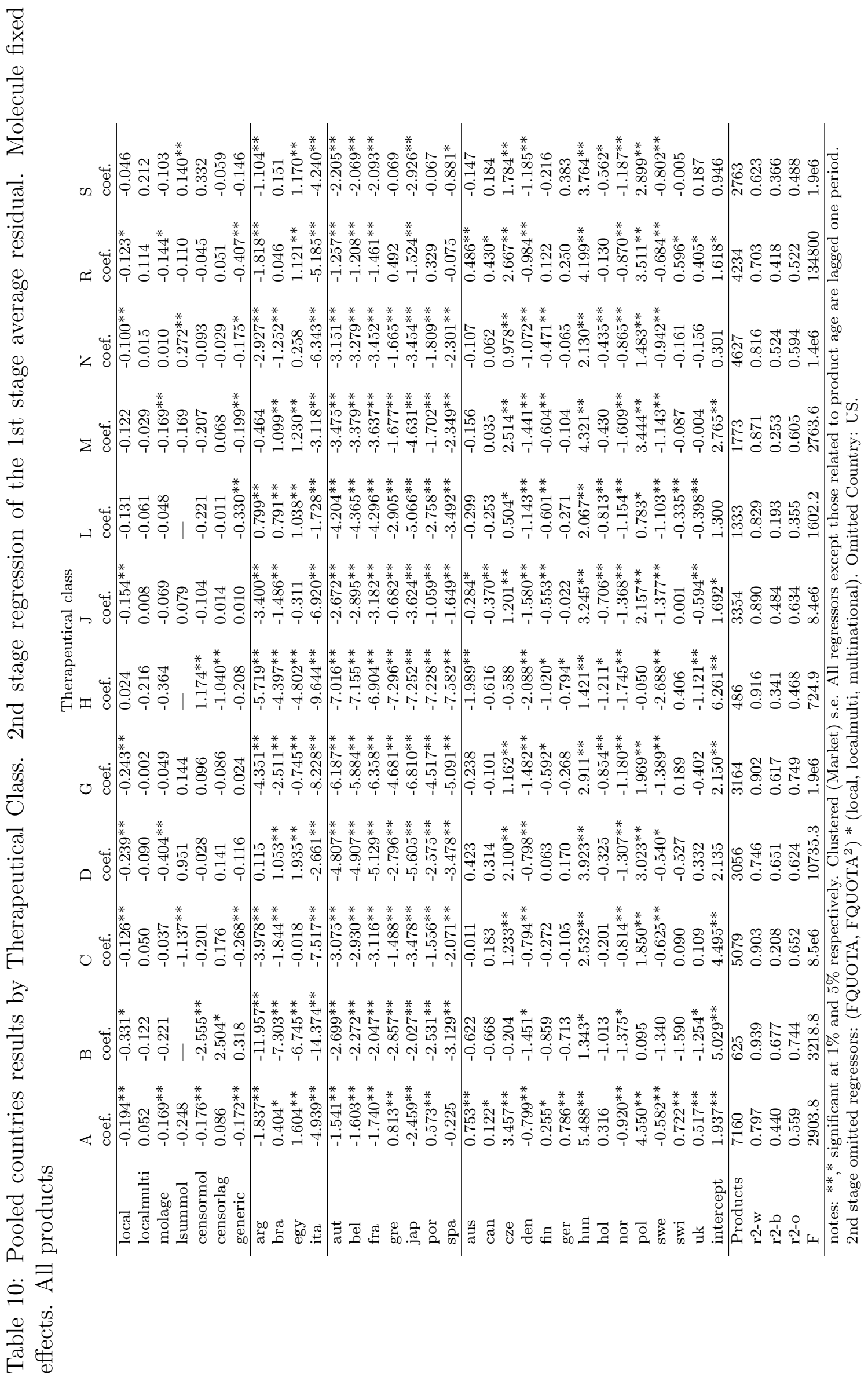

